\title{
Structure of birnessite obtained from decomposition of permanganate under soft hydrothermal conditions. I. Chemical and structural evolution as a function of temperature
}

\author{
Anne-Claire Gaillot ${ }^{1}$ \\ Bruno Lanson ${ }^{1, *}$ \\ Victor A. Drits ${ }^{1,2}$ \\ 1 - Environmental Geochemistry Group, LGIT - Maison des Géosciences, University of \\ Grenoble - CNRS, 38041 Grenoble Cedex 9, France. \\ 2 - Geological Institute, Russian Academy of Sciences, 7 Pyzhevsky street, 109017 Moscow, \\ Russia
}

* Author to whom correspondence should be addressed.

e-mail: Bruno.lanson@obs.ujf-grenoble.fr 


\section{For Table of Contents Use Only}

Structure of birnessite obtained from decomposition of permanganate under soft hydrothermal conditions. I. Chemical and structural evolution as a function of temperature

\section{Anne-Claire Gaillot, Bruno Lanson, Victor A. Drits}

Layers of hydrothermally synthesized birnessite are exclusively built up of $\mathrm{Mn}^{4+}$ octahedra and the layer charge deficit arises solely from the presence of vacant layer sites. When heated to $350^{\circ} \mathrm{C}$, layer $\mathrm{Mn}^{4+}$ cations are partially reduced to $\mathrm{Mn}^{3+}$, leading to the departure of $\mathrm{O}_{\text {layer }}$ atoms. After cooling, layer symmetry is lowered from hexagonal to orthogonal as the result of the segregation of $\mathrm{Mn}^{3+}$-octahedra in rows parallel to the $\mathbf{b}$ axis and by the systematic orientation of their long Mn-O bonds along the a axis. 


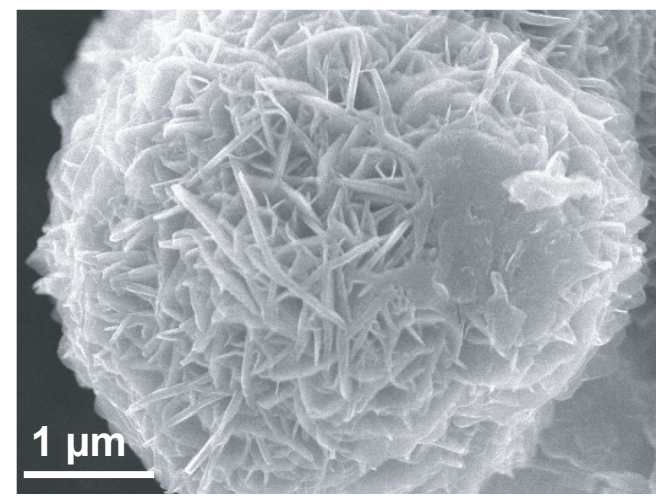

Gaillot et al. - Table of Contents 
The structure of a synthetic K-rich birnessite (KBi) prepared by hydrothermally reacting (4 days at $170^{\circ} \mathrm{C}$ ) a finely ground $\mathrm{KMnO}_{4}$ powder in acidified water was determined. At room temperature the structure of $\mathrm{KBi}$ corresponds to a $3 R^{-}$polytype which can be described as $\mathrm{AbC}_{\mathrm{b}^{\prime}}^{\mathrm{a}^{\prime}} \mathrm{CaB}_{\mathrm{c}^{\prime}}^{\mathrm{a}^{\prime}} \mathrm{BcA}_{\mathrm{b}^{\prime}}^{\mathrm{c}^{\prime}} \mathrm{AbC}$... using the close-packing formalism. Assuming an orthogonal base-centered unit cell, KBi has $a=b \sqrt{ } 3=4.923 \AA, b=2.845 \AA, \gamma=90^{\circ}$ and $c=21.492 \AA$. The layer charge deficit originates exclusively from the presence of vacant layer sites as only $\mathrm{Mn}^{4+}$ cations are present in the octahedral layers, and the following structural formula can be proposed: $\mathrm{K}_{0.296}^{+}\left(\mathrm{Mn}_{0.926}^{4+} \square_{0.074}\right) \mathrm{O}_{2} \cdot 0.40 \mathrm{H}_{2} \mathrm{O}$. The layer charge deficit is compensated by the sole presence of interlayer $\mathrm{K}$ in prismatic cavities located above (or below) an empty tridentate cavity of the lower (or upper) layer and below (or above) a Mn octahedron of the upper (or lower) layer. This site is shifted from the center of the prismatic cavity towards its 
$\mathrm{Mn}^{3+}$-rich rows parallel to the $\mathbf{b}$ axis and by the systematic orientation of their long Mn-O bonds along the a axis.

The origin of the above structural modifications and the nature of the stacking disorder are also determined.

\section{Introduction}

Birnessite has a layer structure consisting of edge-sharing $\mathrm{MnO}_{6}$ octahedra with hydrated cations in the interlayer space compensating for the layer charge deficit which arises either from the coexistence of heterovalent Mn cations within layers or from the presence of vacant layer octahedra. ${ }^{1-5}$ This mineral occurs in diverse geological settings including deep-ocean nodules, ore deposits of $\mathrm{Mn}$ and other metals, soils and alteration crusts. ${ }^{3-19}$ Although present in limited amounts, birnessite plays a pivotal role in the fate of heavy metals and other pollutants in contaminated water systems and soils. ${ }^{18-31}$ This role originates from its unique cation exchange capacity, ${ }^{32-36}$ sorption, ${ }^{36-48}$ and redox properties. ${ }^{21,28,36,45-54}$

To study these properties and the reaction mechanisms involved, synthetic birnessite-like structures are most often used as they are easily obtained under laboratory conditions. Recently, synthetic birnessite has attracted additional attention as a potential cathode material for rechargeable batteries, and extensive research is presently carried out to define optimal conditions for the synthesis of a low-cost and environmentally-safe birnessite-like structure to replace the $\mathrm{LiCoO}_{2}$ cathode commonly used in commercial cells. Birnessite is synthesized either from the oxidation of $\mathrm{Mn}^{2+}$ in a highly alkaline medium, ${ }^{1,2,10,55}$ or from the reduction of $\mathrm{Mn}^{7+}$ using permanganate $\left(\mathrm{MnO}_{4}^{-}\right)$as starting reagent. In the latter case, different protocols have been proposed including mild hydrothermal synthesis, ${ }^{56-58}$ sol-gel processes, ${ }^{59-64}$, interaction of $\mathrm{KMnO}_{4}$ with hydrochloric acid followed by a cation exchange, ${ }^{7,65-67}$ and 
51 thermal decomposition of $\mathrm{KMnO}_{4}$ or of a $\mathrm{MnO}-\mathrm{LiOH}-\mathrm{KNO}_{3}$ mixture at very high 52 temperatures. $^{55,68-70}$

Birnessites obtained by these protocols differ from each other by important structural and

chemical features and by their properties. Therefore, to understand the relationships between structure and properties of the different birnessite varieties a comprehensive crystal chemical study of each variety is required. In the present article and in the companion article structural and chemical features of birnessite samples obtained from the mild hydrothermal treatment of potassium and sodium permanganates are investigated. ${ }^{71}$ From the decomposition at $170^{\circ} \mathrm{C}$ of $\mathrm{KMnO}_{4}$ in acidified water this synthesis protocol initially developed by Chen et al. directly leads to a K-birnessite variety with structural formula $\mathrm{K}_{0.25} \mathrm{MnO}_{2} \cdot 0.6 \mathrm{H}_{2} \mathrm{O} .{ }^{57,58}$ These authors concluded that this birnessite variety has a hexagonal layer symmetry, a three-layer periodicity, and crystallizes in space group $R \overline{3} \mathrm{~m}$. Using the integrated intensity refinement approach they also determined an idealized structure model for this K-birnessite variety. ${ }^{57}$ However, important details of the actual structure of this hydrothermally synthesized birnessite variety were only partially determined. In particular, atomic positions of the different interlayer species ( $\mathrm{K}^{+}$cations and $\mathrm{H}_{2} \mathrm{O}$ molecules) were not differentiated. More important, the average oxidation degree of $\mathrm{Mn}$ and the origin of the layer charge (coexistence of heterovalent Mn cations and/or presence of vacant layer sites) were not determined. In addition, these authors recognized that important issues such as the nature of structural defects in these phyllomanganates needed to be refined. These structural features of Kbirnessite are specifically detailed in the present manuscript. In addition, special attention is paid to the structural modifications observed as a function of temperature. Structural modifications of K-birnessite resulting from cation exchange processes are described in the companion paper. $^{71}$

\section{Experimental Section}


Experimental Methods. K-birnessite (hereafter referred to as $\mathrm{KBi}$ ) was prepared by acidifying $0.025 \mathrm{~mol}$ of finely ground $\mathrm{KMnO}_{4}$ in $50 \mathrm{~mL}$ of water with 5 drops of $4 \mathrm{M} \mathrm{HNO}_{3}$ giving a $\mathrm{pH}$ of $\sim 3$ and a $\mathrm{Mn}: \mathrm{H}^{+}$ratio of $100: 1 .^{57}$ After aging for one month in a light-free environment and under constant stirring, the solution was transferred into a $250 \mathrm{~mL}$ Teflonlined autoclave (Paar bomb), sealed, and reacted hydrothermally for four days at $170^{\circ} \mathrm{C}$. After reaction, the solution $\mathrm{pH}$ was highly alkaline $(\mathrm{pH} \sim 13)$. The resulting black crystals were filtered, washed several times with deionized Milli-Q water (18.2 M $\Omega . \mathrm{cm}^{-1}$ ), then freeze-dried and stored under room conditions for further chemical and structural characterizations.

The morphology of KBi particles was observed on a JEOL JSM 6320F high-resolution scanning electron microscope (SEM) equipped with a field-emission electron source.

Thermal and Chemical Analyses - Structural Formula. Thermal analysis of KBi was carried out with a NETZSCH Simultan STA 409 EP analyzer. DT-TG data were collected in air using a $10^{\circ} \mathrm{C} / \mathrm{min}$ heating rate over the $20-1100^{\circ} \mathrm{C}$ temperature range to determine the amount of structural water, and temperatures characteristic of structural changes.

Total contents of $\mathrm{Mn}$ and interlayer $\mathrm{K}$ were determined using a Perkin-Elmer Optima 3000 ICP-AES after digestion of about $8 \mathrm{mg}$ of birnessite powder in $200 \mathrm{~mL}$ of a $1 \% \mathrm{HNO}_{3}$ / $0.1 \% \mathrm{NH}_{3} \mathrm{OH}$.Cl matrix. The mean oxidation degree of manganese in $\mathrm{KBi}$ was determined by potentiometric titration using $\left(\mathrm{NH}_{4}\right)_{2} \mathrm{Fe}\left(\mathrm{SO}_{4}\right)$ Mohr salt and sodium pyrophosphate. ${ }^{72,73}$ The mean oxidation state, $2 x$, in combination with the atomic ratio $y=\mathrm{K} / \mathrm{Mn}$ determined from the chemical analyses, allows calculating the structural formula of $\mathrm{KBi}$ using the relation: ${ }^{70}$

$$
\mathrm{K}_{2 y / w}^{+}\left(\mathrm{Mn}_{(4 x-6) / w}^{4+} \mathrm{Mn}_{(8-4 x) / w}^{3+} \square_{1-2 / w}\right) \mathrm{O}_{2}
$$


100 where $w=\frac{2 x+y}{2}$, and $\square$ represents vacant layer site. This structural formula can be refined

by taking into account the amounts of interlayer $\mathrm{H}_{2} \mathrm{O}$ molecules deduced from the DT-TG analysis.

X-Ray Diffraction Data Collection. Powder XRD patterns were recorded using a Bruker D5000 powder diffractometer equipped with a Kevex Si(Li) solid detector and CuKa radiation. Intensities were recorded from 5 to $80^{\circ} 2 \theta$, using $0.04^{\circ} 2 \theta$ steps, and a 40 sec counting time per step. A TTK450 Anton Paar chamber was used to record patterns from a KBi sample heated in situ. The initial KBi sample before thermal treatment will be hereafter referred to as sample RoomT-KBi, while $100-\mathrm{KBi}, 150-\mathrm{KBi}, 250-\mathrm{KBi}$ and 350-KBi refer to $\mathrm{KBi}$ samples heated in situ at $100^{\circ} \mathrm{C}, 150^{\circ} \mathrm{C}, 250^{\circ} \mathrm{C}$ and $350^{\circ} \mathrm{C}$, respectively. $\mathrm{KBi}$ sample was heated in situ to the desired temperature at a $6^{\circ} \mathrm{C} / \mathrm{min}$ rate similar to that used for the DT-TG analyses. A 2-hour plateau at fixed temperature was observed before starting XRD data collection so that the sample may reach its thermal equilibrium. All KBi XRD patterns from the temperature series were recorded successively in a single continuous experiment, increasing the temperature stepwise. The AfterT-KBi sample will hereafter refer to the $\mathrm{KBi}$ sample after the complete thermal treatment up to $350^{\circ} \mathrm{C}$ and subsequent cooling to room temperature.

Simulation of Powder XRD Patterns. One of the effective ways to determine the actual structure of defective layered compounds is the calculation of powder XRD patterns using the mathematical formalism described by Drits et al. ${ }^{74}$ This trial-and-error fitting procedure has been successfully used to determine the crystal-chemical structure of different natural and synthetic birnessites containing random stacking faults or consisting of the interstratification of different layer types. ${ }^{8,21,70,75-79}$ Details on the program used to simulate XRD patterns and on the fitting procedure are given by Plançon and Drits et al. ${ }^{75,80,81}$ Specifically, the coherent scattering domains in the layer plane were assumed to have a disk-like shape whose radius 
was adjusted. For each sample, the background was assumed to be linearly decreasing over the angular range. No preferred orientation was considered in agreement with the peculiar geometry of particles clusters revealed by SEM observations. The quality of fit was estimated over the $34^{\circ}-74^{\circ} 2 \theta \mathrm{CuK} \alpha$ range using the usual $R_{\mathrm{wp}}$ parameter.

\section{Results}

Size and Shape of KBi Particles. SEM observations of KBi samples show that these samples consist of ball-like particles having a 2-5 $\mu \mathrm{m}$ diameter (Figures 1a and 1b) as described earlier. ${ }^{57}$ A closer look at these ball-like particles reveals that they actually consist of an aggregate of individual plate-like crystals that are strongly held together and whose maximum length and thickness are $\sim 1 \mu \mathrm{m}$ and $\sim 20 \mathrm{~nm}$, respectively (Figures $1 \mathrm{~b}$ and $1 \mathrm{c}$ ). These crystal shape and dimensions are very similar to those usually reported for natural birnessite crystals or for their synthetic analogues obtained according various protocols, except for the high temperature decomposition of $\mathrm{KMnO}_{4}$ which leads to crystals micrometer-sized along all directions. ${ }^{70}$ A layer 'crust' covering part of the ball-like aggregates is sometime observed (Figure 1b). This peculiar morphology of the aggregates likely prevents the preferential orientation commonly observed for other varieties of natural or synthetic birnessites when prepared for powder XRD analysis.

Loss of Weight During Heating. Thermogravimetric (TG) analysis of KBi shows four distinct losses of weight labeled a-d in Figure 2a. The two low-temperature losses at $\sim 90^{\circ} \mathrm{C}$ and $\sim 140^{\circ} \mathrm{C}$ (a and b) are commonly assumed to correspond to adsorbed and interlayer water whereas the one occurring between $250^{\circ} \mathrm{C}$ and $400^{\circ} \mathrm{C}$ (c) likely corresponds to the loss of oxygen atoms from the octahedral layer framework in relation with the partial reduction of $\mathrm{Mn}^{4+}$ to $\mathrm{Mn}^{3+} \cdot{ }^{57,68}$ A similar reduction of $\mathrm{Mn}^{4+}$ to $\mathrm{Mn}^{3+}$ and loss of structural $\mathrm{O}$ anions has been reported for pyrolusite $\left(\mathrm{MnO}_{2}\right)$ at $\sim 350-400^{\circ} \mathrm{C} .^{82}$ Finally, the strong endothermic peak in 
the DT curve and the associated weight loss at $\sim 890^{\circ} \mathrm{C}$ (d) is most likely related to the melting of $\mathrm{KBi}$.

For sample AfterT-KBi losses of weight are observed at $\sim 90^{\circ} \mathrm{C}, \sim 165^{\circ} \mathrm{C}$, and $\sim 910^{\circ} \mathrm{C}$ (Figure 2b) which correspond to the endotherms a, b, and d, respectively, observed for sample RoomT-KBi. However, in contrast with sample RoomT-KBi, sample AfterT-KBi exhibits a weight gain at $\sim 320^{\circ} \mathrm{C}$, rather than a weight loss.

Chemical Analyses and Structural Formula. The K/Mn atomic ratio $(y=0.320)$ can be calculated from ICP analytical results whereas the $\mathrm{H}_{2} \mathrm{O} / \mathrm{Mn}$ ratio (0.43) is deduced from the $7.51 \%$ weight loss measured between $100^{\circ} \mathrm{C}$ and $220^{\circ} \mathrm{C}$ and corresponding to the loss of structural water. Another $2.7 \%$ weight loss is observed over the $250-400^{\circ} \mathrm{C}$ range. Before the thermal treatment, the structure of RoomT-KBi contains only $\mathrm{Mn}^{4+}$ cations as the measured oxidation state of $\mathrm{Mn}$ is equal to $4.00 \pm 0.02$, and its structural formula can thus be written as:

$$
\mathrm{K}_{0.296}^{+}\left(\mathrm{Mn}_{0.926}^{4+} \square_{0.074}\right) \mathrm{O}_{2} \cdot 0.40 \mathrm{H}_{2} \mathrm{O}
$$

In contrast, the oxidation state measured for $\mathrm{Mn}$ in the AfterT-KBi sample is much lower (3.78 \pm 0.02 ), showing that AfterT-KBi sample contains $\sim 22 \%$ of $\mathrm{Mn}^{3+}$ and $\sim 78 \%$ of $\mathrm{Mn}^{4+}$ cations if the relative proportion of $\mathrm{Mn}^{2+}$ is assumed to be negligible. In addition, the $6.4 \%$ weight loss measured between $100^{\circ} \mathrm{C}$ and $230^{\circ} \mathrm{C}$ after rehydration corresponds to the loss of structural water. If the $\mathrm{K} / \mathrm{Mn}$ ratio is unchanged after the rehydration of the heated $\mathrm{KBi}$ sample at room temperature, the structural formula of AfterT-KBi can be written as:

$$
\mathrm{K}_{0.312}^{+}\left(\mathrm{Mn}_{0.761}^{4+} \mathrm{Mn}_{0.215}^{3+} \square_{0.024}\right) \mathrm{O}_{2} \cdot 0.37 \mathrm{H}_{2} \mathrm{O}
$$

Indexing of the Experimental XRD Patterns. Figure 3 compares the XRD patterns of $\mathrm{KBi}$ recorded at room temperature (before and after thermal treatment) and at temperatures ranging from $100-350^{\circ} \mathrm{C}$. Following their indexing as described below, experimental and calculated $d(h k \ell)$ values are listed in Table 2 for all KBi samples and the corresponding unitcell parameters are reported in Table 1 . Note that Table 1 also contains the unit-cell parameters of additional phases identified in samples $100-\mathrm{KBi}, 350-\mathrm{KBi}$ and AfterT-KBi 
samples while fitting their respective XRD patterns with the trial-and-error approach described by Drits et al. ${ }^{74}$

Sample RoomT-KBi. The XRD pattern of RoomT-KBi can be indexed using a three-layer rhombohedral (3R) unit cell having $a_{\mathrm{rh}}=b_{\mathrm{rh}}=2.845 \AA, \gamma=120^{\circ}$ and $c=21.492 \AA$ (space group $R \overline{3} m$ ) as described by Chen et al. ${ }^{57}$ However, for later needs, the indexation was performed systematically with an orthogonal base-centered unit cell having $a_{\text {ort }}=a_{\mathrm{rh}} \sqrt{3}=$ $4.923 \AA, b_{\text {ort }}=b_{\mathrm{rh}}=2.845 \AA, \gamma=90^{\circ}$ and $c=21.492 \AA$ (Table 1). Going from low- to highangle values, the powder XRD pattern of RoomT-KBi (Figure 3a) contains a rational series of basal reflections with a $d(003)$ value corresponding to a minimum periodicity of $7.164 \AA$ along the $\mathbf{c}^{*}$ axis followed by two families of $h k \ell$ reflections having for indices i) $20 \ell(\ell=3 n$ +1 , n integer) and $11 \ell(\ell=3 \mathrm{n}-1)$ over the $34^{\circ}-80^{\circ} 2 \theta$ range, ii) $31 \ell$ and $02 \ell(\ell=3 \mathrm{n})$ over the $64^{\circ}-80^{\circ} 2 \theta$ range.

Heated-KBi Samples. XRD patterns obtained during heating of KBi sample are very similar to that recorded on the initial RoomT-KBi sample and can also be indexed using $3 R$ unit cells (unit-cell parameters being hereafter expressed in the orthogonal system). Figures 3b-d show that only intense dehydration occurs when heating the sample up to $250^{\circ} \mathrm{C}$ thus inducing a significant decrease of the $d(003)$ value down to 6.46-6.42 $\AA$ and related shifts of non-basal reflections (Table 2). Figure 4 shows that the decrease of $c$ parameter is accompanied by a limited increase of $a(=b \sqrt{3})$ and $b$ unit-cell parameters (Table 1$)$, the hexagonal layer symmetry being preserved up to that temperature $\left(a=b \sqrt{3}, \gamma=90^{\circ}\right)$. In contrast, a dramatic increase of the lateral dimensions of the layer was observed $(b=2.868 \AA$ - Table 1 - Figure 4) when heating the sample to $350^{\circ} \mathrm{C}$. A careful examination shows that with increasing temperatures $00 \ell$ diffraction lines are broadened and that their asymmetry is increased. For example, the tail which is present on the low-angle side of both 003 and 006 reflections above $100^{\circ} \mathrm{C}$ results in a shoulder at $350^{\circ} \mathrm{C}$ (inset on Figure 3e) thus suggesting 
202 the presence of crystals with a larger dimension along the $\mathbf{c}^{*}$ axis. When temperature is increased to $350^{\circ} \mathrm{C}$, $h k \ell$ reflections are broadened in addition to $00 \ell$ ones, the profiles of some of these reflections becoming asymmetrical. In addition, for some of theses $h k \ell$ reflections the mismatch between measured and calculated $d(h k \ell)$ values exceeds the experimental error (Table 2). As discussed below, these specific features of experimental XRD profiles are related to the heterogeneous phase composition of sample 350-KBi.

Sample AfterT-KBi. Following the thermal treatment up to $350^{\circ} \mathrm{C}$, the XRD pattern recorded at room temperature on sample AfterT-KBi is dramatically modified as compared to those of both RoomT-KBi and 350-KBi. The diffraction pattern can be indexed assuming a one-layer monoclinic unit cell $(1 M)$ with $a=5.130 \AA, b=2.850 \AA, c=7.131 \AA, \beta=101.0^{\circ}$ (space group $C 2 / m$ ). The octahedral layers of AfterT-KBi have thus an orthogonal symmetry with $a>b \sqrt{3}$ whereas all other samples had a hexagonal layer symmetry. Adjacent layers are shifted with respect to each other by $c \cdot \cos \beta=-0.260 a$ along the $\mathbf{a}$ axis, and the basal spacing $d(001)$ is equal to $c \cdot \sin \beta=7.000 \AA$. As for sample $350-\mathrm{KBi}, h k \ell$ reflections of AfterT-KBi have broad and asymmetrical profiles and for some of them a noticeable discrepancy between $d_{\exp }(h k \ell)$ and $d_{\text {cal }}(h k \ell)$ can be observed (Table 2). It will be shown below that these specific features of experimental XRD profiles are related to the heterogeneous phase composition of sample AfterT-KBi.

\section{Quantitative Structure Determination.}

Layer Stacking Sequence of the 3R Samples. In agreement with previous reports, ${ }^{57}$ RoomT-KBi sample was indexed with a three-layer rhombohedral (3R) unit cell in space group $R \overline{3} m$. However, two distinct structure models match these requirements. Using the close-packing formalism, these idealized models are described as:

$$
\mathrm{AbC}_{\mathrm{b}^{\prime}}^{\mathrm{a}^{\prime}} \mathrm{CaB}_{\mathrm{c}^{\prime}}^{\mathrm{a}^{\prime}} \mathrm{BcA}_{\mathrm{b}^{\prime}}^{\mathrm{c}^{\prime}} \mathrm{AbC} \ldots \quad\left(3 R^{-}\right)
$$

$\mathrm{AbC}_{\mathrm{a}}, \mathrm{BcA}_{\mathrm{b}}, \mathrm{CaB}_{\mathrm{c}}, \mathrm{AbC} \ldots$ 
where $\mathrm{A}, \mathrm{B}$ and $\mathrm{C}$ represent the positions of layer oxygen atoms $\left(\mathrm{O}_{\text {layer }}\right), \mathrm{a}, \mathrm{b}$ and $\mathrm{c}$ the positions of the layer $\mathrm{Mn}$ cations ( $\left.\mathrm{Mn}_{\text {layer }}\right)$ and $\mathrm{a}$ ', b' and c' the positions of interlayer $\mathrm{K}$ cations. In the first model ( $3 R^{-}$polytype), adjacent layers are shifted with respect to each other by $-a / 3$ along the a axis, thus leading to the prismatic coordination of interlayer species. In the second model ( $3 R^{+}$polytype), adjacent layers are shifted with respect to each other by $+a / 3$ along the a axis, interlayer species being then octahedrally coordinated. For the two polytypes, diffraction lines have identical positions but differ by their relative intensities. The intensity of the $20 \ell(\ell=3 n+1)$ reflections is indeed much lower than that of $11 \ell(\ell=3 n-1)$ reflections for the $3 R^{-}$polytype, whereas the $20 \ell$ reflections of the $3 R^{+}$polytype are more intense than the $11 \ell$ ones (Figure 5a). The total intensity calculated for overlapped $31 \ell$ and $02 \ell(\ell=3 n)$ reflections are similar for the two stacking modes. From the comparison of their experimental XRD patterns (Figure 3) with those calculated for the two polytypes, RoomT$\mathrm{KBi}$ and all heated samples clearly correspond to the $3 R^{-}$polytype, their layers being systematically shifted with respect to each other by $-a / 3$ along the a axis.

Sample RoomT-KBi. In the initial structure model, $\mathrm{Mn}_{\text {layer }}$ was located at the origin of the unit cell, and $\mathrm{O}_{\text {layer }}$ had coordinates $(0.333,0, \pm 0.046)$ to match the $2.00 \AA$ layer thickness previously reported for phyllomanganates. ${ }^{70,75-79,83,84}$. In agreement with the proposed structural formula (eq 2) it was initially assumed that 0.924 Mn cations are present per layer octahedron. According to Chen et al., ${ }^{57}$ both interlayer $\mathrm{K}^{+}$cations and $\mathrm{H}_{2} \mathrm{O}$ molecules are located on the faces of the trigonal prisms formed by $\mathrm{O}_{\text {layer }}$ from adjacent layers (Figure 6 Position 1). For high-temperature K-birnessite with a similar layer octahedral composition, Gaillot et al. proposed an alternative position in the center of the interlayer prismatic cavity (Figure 6 - Position 2). ${ }^{70}$ In this alternative position, $\mathrm{K}$ is located above (or below) the empty tridentate cavity of the lower (or upper) layer and below (or above) a vacant or occupied Mn octahedron of the upper (or lower) layer. The intensity distributions calculated for $20 \ell$ and 
$11 \ell$ reflections assuming either model are compared in Figure 7a to the experimental XRD patterns of KBi samples. In both cases, calculated and experimental XRD patterns are similar and the solution does not appear univocal. Contrastingly, the intensity distribution of $31 \ell$ and $02 \ell$ reflections is extremely sensitive to the atomic coordinates of interlayer species. Specifically, after normalization of the calculated 310/020 maximum to the experimental one, the calculated 313/023 reflection is significantly lower than the experimental one when $\mathrm{K}^{+}$is located in the center of the trigonal prisms and higher when $\mathrm{K}^{+}$is located in the prism's faces (Figure 7b). The intensity ratio between these two diffraction maxima can thus be used to constrain the position of interlayer $\mathrm{K}^{+}$cations, and the XRD simulations has thus been performed over the $34^{\circ}-74^{\circ} 2 \theta$ range for all $\mathrm{KBi}$ samples to include $31 \ell$ and $02 \ell$ reflections along with $20 \ell$ and $11 \ell$ ones. The best fit to the experimental XRD pattern (Figure 7b) was obtained when within each interlayer prism the site of $\mathrm{K}^{+}$is split, $\mathrm{K}^{+}$being shifted from the center of the prism towards its faces [Figure 6 - Position 3; $(-0.24,0,0.167)$ ]. A similar position for interlayer $\mathrm{K}^{+}$cations site was refined for high-temperature $\mathrm{KBi}$ samples with a similar layer octahedral composition. ${ }^{70}$ In the optimum structure model for sample RoomT$\mathrm{KBi}, \mathrm{H}_{2} \mathrm{O}$ molecules were located in the center of the interlayer space shifted from the edges of the trigonal prisms towards their centers, in six positions equivalent to $(0.5,0,0.167)$ (Position 4 - Figure 6). The inter-atomic distance between these $\mathrm{H}_{2} \mathrm{O}$ molecules and the nearest $\mathrm{O}_{\text {layer }}$ from adjacent layers $\left(\mathrm{O}_{\text {layer }}-\mathrm{H}_{2} \mathrm{O}=2.707 \AA\right.$ with a $\mathrm{O}_{\text {layer }}-\mathrm{H}_{2} \mathrm{O}-\mathrm{O}_{\text {layer }}$ angle equal to $144.7^{\circ}$ ) allows the formation of strong H-bonds which contribute significantly to the cohesion between layers.

However, when only the above phase is considered, a significant misfit to the experimental XRD pattern is visible at the tails of each diffraction maximum (Figure $5 \mathrm{~b}$ $R_{\mathrm{wp}}=15.77 \%$ ). This misfit was assumed to result from the presence in sample RoomT-KBi of an additional fine-grained phase whose structure is identical to that of the main phase but exhibiting a high structural disorder. The contribution of this very disordered phase (Figure 
5c) has been included in all simulations to improve fit quality. This phase possibly corresponds to the material holding $\mathrm{KBi}$ crystals together and sometimes forming a "crust" over the ball-like aggregates (Figure 1b). Accordingly, the best fit to the RoomT-KBi experimental data (Figure $5 \mathrm{~d}-R_{\mathrm{wp}}=8.90 \%$ ) was obtained for a physical mixture (70:30 ratio) of a well-crystallized $3 R^{-}$phase containing $5 \%$ of random stacking faults $\left(\mathrm{W}_{\mathrm{R}}\right)$ and of a quasi-turbostratic phase $\left(\mathrm{W}_{\mathrm{R}} \sim 75 \%\right)$ having a smaller coherent scattering domain size (CSDS) in the ab plane (70 $\AA$ vs $300 \AA$ ). In the quasi-turbostratic phase, adjacent layers with a well-defined stacking mode are shifted with respect to each other by $-a / 3$ along the $\mathbf{a}$ axis. Although present in small proportion in the main $3 R^{-}$phase $\left(\mathrm{W}_{\mathrm{R}}=5 \%\right)$, random stacking faults significantly increase the width of $20 \ell / 11 \ell$ reflections with increasing $\ell$ index (data not shown). This peak broadening, together with the presence of the poorly crystalline phase, impaired the use of conventional structure refinement techniques, including the Rietveld technique. As a consequence the structural characterization of $\mathrm{KBi}$ samples was performed with the trial-and-error method described by Drits et al. $^{74}$ Atomic coordinates, site occupancies and other structural parameters used to obtain the best possible agreement between experimental and calculated XRD patterns are listed in Table 3 whereas selected inter-atomic distances are reported in Table 4.

Sample 100-KBi. The main structural features of 100-KBi XRD pattern are essentially unchanged, as compared to that of RoomT-KBi. Interlayer water was assumed to be present in most interlayers, in agreement with the DT-TG data which indicates that only adsorbed $\mathrm{H}_{2} \mathrm{O}$ molecules were lost at $100^{\circ} \mathrm{C}$ (first endothermic DT peak at $\sim 90^{\circ} \mathrm{C}$ ) and with the limited decrease of the unit-cell $c$ parameter. The structure model determined for sample RoomT$\mathrm{KBi}$ was thus used as a starting point for calculation of XRD patterns, after adjusting unit-cell parameters to match the experimentally determined peak positions. The $x$ coordinate of interlayer $\mathrm{H}_{2} \mathrm{O}$ molecules was changed (from 0.500 to 0.450 - Table 3) to better match the experimental distribution of intensity (Figure $8 \mathrm{a}-R_{\mathrm{wp}}=18.59 \%$ ). In addition, the degree of 
structural ordering and the crystallinity of $\mathrm{KBi}$ was found to be lower at $100^{\circ} \mathrm{C}$ than at room temperature. The proportion of random stacking faults was indeed increased from 5 to $12 \%$ in the ordered structure, whereas its CSDS in the ab plane was decreased from 300 to $230 \AA$. The shoulder on the high-angle side of the 115 maximum which is visible on $100-\mathrm{KBi}$ experimental pattern (arrow - Figure 8a) was reproduced assuming the presence of a mixedlayer structure (MLS - Figure 8b). In this MLS, 30\% of the layers are identical to the ones in the main ordered phase. The remaining $70 \%$ have the same layer structure but no interlayer water, and thus exhibit a lower unit-cell $c$ parameter (Table 1 - Figure 8b). Other structural parameters such as unit-cell $b$ parameter, cation occupancy of the $\mathrm{Mn}_{\text {layer }}$ site, and position of interlayer $\mathrm{K}^{+}$were identical to those determined for sample RoomT-KBi (Table 3). The partial dehydration observed in the accessory MLS is in agreement with the DT-TG results, and with the tailing of the 006 reflection towards high angles. The best fit to the experimental data (Figure 8c $-R_{\mathrm{wp}}=12.24 \%$ ) was obtained for a physical mixture of $77 \%$ of a fully hydrated periodic $3 R^{-}$polytype, $8 \%$ of the accessory and partially dehydrated MLS, and $15 \%$ of a poorly crystalline phase exhibiting a quasi-turbostratic stacking ( $\left.\mathrm{W}_{\mathrm{R}} \sim 75 \%\right)$ and a small CSDS in the ab plane (70 $)$. Structural parameters characterizing the optimal model for hydrated layers and selected inter-atomic distances are listed in Tables 3 and 4, respectively. Parameters of the dehydrated layers are similar to those determined for sample $150-\mathrm{KBi}$ and reported in Table 3.

Sample $150-\mathrm{KBi}$. DT-TG results show that at $150^{\circ} \mathrm{C} \mathrm{KBi}$ dehydration is complete as the endotherm maximum was obtained at $\sim 140^{\circ} \mathrm{C}$. Accordingly, the XRD pattern reveals a much smaller periodicity along the $\mathbf{c}^{*}$ direction $(d(003)=6.494 \AA)$ leading to a strong decrease of the unit-cell $c$ parameter. Simultaneously, the unit-cell $b$ parameter is slightly enlarged most likely as the result of an increased thermal motion and/or to better accommodate the presence of $\mathrm{K}^{+}$cations in dehydrated interlayers. Apart from the shift of diffraction lines due to the collapse of KBi layers, the experimental XRD pattern of sample 150-KBi looks essentially 
similar to those obtained at lower temperatures indicating that the structure of $\mathrm{KBi}$ is essentially unaffected by the dehydration. Consistently, in the optimum structure model $\mathrm{K}^{+}$ cations were located at the interlayer mid-plane, and shifted towards the faces of the prismatic cavities in 6 positions equivalent to $(-0.27,0,0.167)$, although $\mathrm{H}_{2} \mathrm{O}$ molecules were no longer present in the interlayer space. Note that this structure model is very similar to that determined for the dehydrated layers present in sample 100-KBi. The two models differ from each other only by the lateral unit-cell dimensions and interlayer $\mathrm{K}^{+}$cations positions (Tables 1 and 3). The best fit to the experimental data (Figure $8 \mathrm{~d}-R_{\mathrm{wp}}=8.92 \%$ ) was obtained for a physical mixture of $61 \%$ of a well-crystallized phase $\left(\mathrm{W}_{\mathrm{R}}=10 \%\right.$, CSDS in the ab plane $=$ $230 \AA$ ) and $39 \%$ of a quasi-turbostratic phase $\left(\mathrm{W}_{\mathrm{R}} \sim 75 \%\right.$, CSDS $=70 \AA$ ). Structural parameters characterizing the optimal model and selected inter-atomic distances are listed in Tables 3 and 4, respectively.

Sample 250-KBi Model. The structure model determined for sample 250-KBi is also similar to the ones described above, although both the degree of structural ordering and the crystallinity keep degrading. The main ordered phase contains indeed $17 \%$ of random stacking faults, its average CSDS in the ab plane being $180 \AA$. The relative proportion of the quasi-turbostratic phase providing the best fit to the experimental data (Figure $8 \mathrm{e}-R_{\mathrm{wp}}=$ 9.97\%) is $25 \%$. Structural parameters characterizing the optimal model and selected interatomic distances are listed in Tables 3 and 4, respectively.

Sample 350-KBi. The structure can be described to a large extent as a $3 R^{-}$polytype, but significant structural changes are visible on the XRD pattern of 350-KBi (Figure 3e). In particular, the shoulder on the low-angle side of the 006 maximum (inset on Figure 3e) suggests the presence of layers with an interlayer spacing larger than that of the main phase. In addition, there is a strong increase of the unit-cell $b$ parameter from 2.845 -2.851 $\AA$ (25$250^{\circ} \mathrm{C}$ ) to $2.868^{\circ} \mathrm{C}$ at $350^{\circ} \mathrm{C}$ (Table 1 , Figure 4) although layer symmetry remains hexagonal. This abrupt and dramatic increase cannot result solely from thermal motion as the unit-cell 
dilatation usually depends linearly on the temperature if the structure or the electronic state (for redox sensitive elements) is not modified. Rather, it is likely that at this temperature $\mathrm{Mn}^{4+}$ was partially reduced to $\mathrm{Mn}^{3+}$. As a result, $<\mathrm{Mn}-\mathrm{O}>$ distance was increased and lateral dimensions of the unit cell were enlarged to accommodate this augmentation. $<\mathrm{Mn}-\mathrm{O}>$ increases indeed from $1.912 \AA$ for $\mathrm{Mn}^{4+}$ (determined for $\left.\lambda-\mathrm{MnO}_{2}\right)^{85}$ to $2.04 \AA$ for $\mathrm{Mn}^{3+}$ in crednerite and other Mn-oxyhydroxides. ${ }^{86-88,89, \text { Norrestam, } 1967 ~ \# 789}$ As a consequence of the presence of trivalent $\mathrm{Mn}_{\text {layer }}$, the layer charge deficit was assumed to derive essentially from the coexistence of heterovalent $\mathrm{Mn}_{\text {layer }}$ cations within the octahedral layer and no $\mathrm{Mn}$ vacant sites were considered in the structure model of 350-KBi (see structural formula - eq 3). Apart from the occupancy of the $\mathrm{Mn}_{\text {layer }}$ site, atomic coordinates and occupancies of the various sites were considered to be identical to those determined for sample $250-\mathrm{KBi}$. The resulting $3 R^{-}$structure allowed reproducing the main features of the experimental diffraction pattern, except for the strong shoulder on the low-angle side of the 115 reflection which is visible only for sample 350-KBi (arrow on Figure 9a). The position of this shoulder is close to that of the 204 reflection of $3 R$ varieties, this reflection being extremely weak for the $3 R^{-}$polytype but strong for the $3 R^{+}$polytype (Figure $5 a$ ). Layers stacked with a $+a / 3$ interlayer displacement along the a axis (polytype $3 R^{+}$) are thus likely present in sample $350-\mathrm{KBi}$. Since the 204 maximum appears as a broad shoulder tailing towards the 115 reflection of the $3 R^{-}$polytype, it is likely that $3 R^{+}$and $3 R^{-}$structural fragments coexist within the same crystals. The diffraction effects resulting from the interstratification of $3 R^{+}$and $3 R^{-}$structural fragments within the same crystallites may be predicted from the considerations developed by Drits and coworkers. ${ }^{75,90,91}$ By applying Méring's approach, which was developed initially for $00 \ell$ reflections, to $h k \ell$ reflections Drits and coworkers were able to demonstrate that the diffraction maxima observed for the MLS resulting from the random interstratification of fragments of periodic structures having similar layer structure but different interlayer displacements are located between the maxima corresponding to the individual periodic 
structures. The actual position and intensity of these reflections depend on the proportion of each type of the interstratified fragments. ${ }^{90-92}$ As for clay minerals, ${ }^{90}$ this type of structural defect is common in birnessite. ${ }^{70,76,78,79}$ In agreement with the above considerations, the 204 shoulder at $\sim 41.5^{\circ} 2 \theta$ in the 350 -KBi XRD pattern was thus reproduced (Figure 9b) with the contribution of a MLS containing $30 \%$ of layers shifted by $-a / 3$ along the a axis (A layers, corresponding to fragments of a $3 R^{-}$polytype) and $70 \%$ of layers shifted by $+a / 3$ along the a axis (B layers, corresponding to fragments of a $3 R^{+}$polytype). The two layer types were randomly interstratified, and they both had unit-cell parameters $a=4.997 \AA$, and $b=2.885 \AA$. The interlayer configuration within B fragments ( $3 R^{+}$polytype) is different from that in the A fragments because of the different layer stacking mode. In the former fragments, interlayer $\mathrm{K}^{+}$cations have an octahedral rather than prismatic coordination and were found to be located in position (-0.3, 0, 0.167 - Figure 10). With respect to a given layer, this position of interlayer $\mathrm{K}^{+}$, above and below the empty tridentate cavity of adjacent octahedral layers, is similar to that in the A layers.

The best fit to the experimental XRD pattern (Figure 9c $-R_{\mathrm{wp}}=9.92 \%$ ) was obtained for a physical mixture of quasi-periodic $3 R^{-}$crystals (95:5 ratio between $\mathrm{A}$ and $\mathrm{B}$ layers, respectively $-\mathrm{W}_{\mathrm{R}}=10 \%$ ), a $3 R^{-} / 3 R^{+}$MLS (30:70 ratio between A and B layers, respectively $\left.-\mathrm{W}_{\mathrm{R}}=30 \%\right)$, and a quasi-turbostratic structure $\left(\mathrm{W}_{\mathrm{R}}=75 \%-3 R^{-}\right.$ordered layer stacking $)$in a 40:20:40 ratio. The CSDS in the ab plane is slightly larger for 350-KBi crystals as compared to $250-\mathrm{KBi}$ crystals (230 $\AA$ and $200 \AA$ for the quasi-periodic $3 R^{-}$structure and the MLS, respectively, as compared to $180 \AA$ ).

Sample AfterT-KBi. XRD patterns of KBi recorded at room temperature before and after the thermal treatment differ strikingly (Figures 3a and 3f). Specifically, whereas the RoomT$\mathrm{KBi}$ sample was dominated by a $3 R^{-}$periodic structure, simulation of its XRD patterns showed that sample AfterT-KBi consisted of two phases present in equal proportions. In one of the phases $90 \%$ of the layers are stacked according to a monoclinic $1 M$ structure. These 
layers are interstratified with layers forming $3 R^{-}$structural fragments (Figure $11 \mathrm{a}-\mathrm{R}_{\mathrm{wp}}=$ 23.03\%). The layers forming the $1 M$ and $3 R^{-}$subsequences are partially incommensurate. $1 M$ layers exhibit an orthogonal layer symmetry with unit-cell parameters $a_{\text {ort }}=5.130 \AA, b_{\text {ort }}=$ $2.850 \AA\left(a_{\text {ort }}>b_{\text {ort }} \sqrt{ } 3\right), c=7.131 \AA, \beta=101.0^{\circ}, T x=c \cdot \cos \beta=-0.260 a$. Unit-cell parameters of the $3 R^{-}$fragments present in sample AfterT-KBi $\left(a_{\text {ort }}=b_{\text {ort }} \sqrt{3}=4.971 \AA, b_{\text {ort }}=2.870 \AA, c=\right.$ $21.150 \AA)$ are considerably increased as compared to those reported for RoomT-KBi $\left(a_{\text {ort }}=\right.$ $4.923 \AA, b_{\text {ort }}=2.845 \AA, c=21.492 \AA$ - Table 1, Figure 4). This increase is consistent with the structural formula proposed for this sample (eq 3) which indicates the presence of a significant proportion of $\mathrm{Mn}^{3+}$ cations in vacancy-free layers. As indicated by their orthogonal layer symmetry, $1 M$ layers also contain a significant proportion of $\mathrm{Mn}^{3+}$ cations in vacancy-free layers. In these latter layers, interlayer $\mathrm{K}^{+}$cations and $\mathrm{H}_{2} \mathrm{O}$ molecules are located in $(-0.40,0,0.5)$ and $(-0.45,0,0.5)$, respectively (Figure 12 - Tables 4, 5). These positions are similar to the main undifferentiated $\left(\mathrm{K}, \mathrm{H}_{2} \mathrm{O}\right)$ position found by Post and Veblen $(-0.413,0,0.5),{ }^{83}$ provided that their $x$ position is given in projection normal to the ab plane. As both types of interstratified layer fragments consist of vacancy-free layers and likely contain a similar proportion of $\mathrm{Mn}^{3+}$, the origin of their incommensurability is to be sought in the orientation distribution of distorted $\mathrm{Mn}^{3+}$ layer octahedra (see Discussion). As a result of the thermal treatment and of the induced chemical and structural modifications, the $1 \mathrm{M} / 3 \mathrm{R}^{-}$ MLS contains a high proportion of random stacking faults $\left(\mathrm{W}_{\mathrm{R}}=25 \%\right)$ as compared to lowto-medium temperature $\mathrm{KBi}$ samples $\left(\mathrm{W}_{\mathrm{R}}=5-17 \%\right.$ for RoomT-, 100-, 150-, and 250-KBi samples).

The second phase present in sample AfterT-KBi was poorly crystallized (CSDS in the ab plane $=70 \AA)$ and possessed a quasi-turbostratic structure $\left(\mathrm{W}_{\mathrm{R}}=75 \%\right) .3 R^{-}$and $1 M$ structural fragments coexist in a 4:1 ratio among layers having a well-defined stacking (random interstratification - Figure 11b). Both $3 R^{-}$and $1 M$ layers are identical in the two phases (unitcell parameters, coordinates and occupancies of the different sites - Table 4), and it was 
assumed that randomly stacked layers had the same lateral dimensions as $3 R^{-}$layers. The best fit to the experimental $\mathrm{XRD}$ pattern is shown in Figure 11c $\left(R_{\mathrm{wp}}=8.67 \%\right)$. Structural parameters characterizing the optimal model for both $3 R^{-}$and $1 M$ fragments and selected inter-atomic distances are listed in Tables 3 and 4, respectively.

\section{Discussion}

The determination of structure models for all KBi samples allowed complementing our knowledge of crystal chemistry and structure of $\mathrm{KBi}$ obtained from the decomposition of $\mathrm{KMnO}_{4}$ under mild hydrothermal conditions and of their modifications upon temperature increase. In the following, the origin of the layer charge will be determined in the original sample and as a function of temperature along with structural changes. In particular the partial reduction of $\mathrm{Mn}_{\text {layer }}$ and the migration of vacant sites within layer, which is associated to the departure of $\mathrm{O}_{\text {layer }}$, will be discussed. Finally, the location of interlayer species will be analyzed as a function of temperature from its influence of layer structure stability.

\section{Crystal-Chemistry of Sample RoomT-KBi}

Cation Composition and Layer Structure. Titration of Mn oxidation degree shows that the $\mathrm{Mn}$ oxidation state is reduced from +VII to +IV when $\mathrm{KBi}$ is obtained from the hydrothermal decomposition of $\mathrm{KMnO}_{4}$ and that no $\mathrm{Mn}^{3+}$ is formed. To our present knowledge, this protocol is actually the only abiotic one that allows obtaining synthetic birnessite crystals exhibiting a three-dimensional ordering and containing only $\mathrm{Mn}^{4+}$ cations, which seems to be an important feature for electrochemical applications. ${ }^{69}$ From the reduction of $\mathrm{KMnO}_{4}$ by $\mathrm{MnCl}_{2}$ in near neutral conditions Villalobos et al. also synthesized a birnessite sample $\left(\delta-\mathrm{MnO}_{2}\right)$ containing only $\mathrm{Mn}^{4+}$ cations in the octahedral layers, but this birnessite was totally turbostratic $\left(\mathrm{W}_{\mathrm{R}}=100 \%\right)$ and presented extremely limited development of the layers in the ab plane. ${ }^{93}$ 
In agreement with the sole presence of $\mathrm{Mn}^{4+}$ cations within octahedral layers, individual and average Mn-O distances are equal to $1.92 \AA( \pm 0.01)$ in RoomT-KBi. This value is indeed typical for $\mathrm{MnO}_{2}$ compounds. ${ }^{87}$ For example, similar $<\mathrm{Mn}$-O $>$ distances were reported in the $\mathrm{Mn}^{3+}$-free layers of chalcophanite $(1.923 \AA)$ and of $\lambda-\mathrm{MnO}_{2}(1.912 \AA) .{ }^{85,94}$ As a consequence, KBi layers likely contain $\sim 7 \%$ of vacant octahedra which represent the sole source of layer charge deficit, in agreement with the proposed structural formula (eq 2). The layer cation composition and the source of layer charge deficit in hydrothermal $\mathrm{KBi}$ are thus similar to those observed for the sample $\mathrm{KBi}_{8}$ obtained from the thermal decomposition of $\mathrm{KMnO}_{4}$ at $800^{\circ} \mathrm{C}$ whose $\mathrm{Mn}^{3+}$-free layers contain $12 \%$ of vacant octahedra. ${ }^{70}$ As in other phyllomanganates, octahedra building up KBi layers are flattened along the $\mathbf{c}^{*}$ axis as a result of the electrostatic repulsion between adjacent $\mathrm{Mn}_{\text {layer }}$. The length of shared O-O edges in RoomT-KBi crystals (2.59 $\AA$ ) is thus shorter than that of O-O edges on the basal surfaces of the crystals (2.84 $\AA$ - Table 4).

Interlayer Structure. Interlayer $\mathrm{K}^{+}$cations occupy one of the six positions equivalent to the $(-0.24,0,0.167)$ site (Position 3 - Figure 6a). Each site in the interlayer mid plane is shifted from one face of the prism towards its center. Interlayer $\mathrm{K}^{+}$cations are coordinated by four $\mathrm{O}_{\text {layer }}$ atoms at $\sim 2.970 \AA$. Two $\mathrm{H}_{2} \mathrm{O}$ molecules at $2.924 \AA$ and $3.222 \AA$ complete their first coordination shell. These short $\mathrm{K}-\mathrm{O}_{\text {layer }}$ bond lengths significantly contribute to the cohesion between adjacent layers, together with short $\mathrm{H}_{2} \mathrm{O}-\mathrm{O}_{\text {layer }}$ distances (2.705 $\AA$ ) which allow for strong $\mathrm{H}$-bonds. The shift of interlayer $\mathrm{K}^{+}$cations from the center of the prism decreases unfavorable electrostatic repulsion with the nearest $\mathrm{Mn}_{\text {layer }}$. The position determined for interlayer $\mathrm{K}^{+}$cations in RoomT-KBi is similar to that refined on a $\mathrm{KBi}_{8}$ monocrystal in which average K-O distances were also compatible with a 6-fold coordination (4 $\mathrm{O}_{\text {layer }}$ and $\left.2 \mathrm{H}_{2} \mathrm{O}\right) .^{70}$

In contrast to sample $\mathrm{KBi}_{8}$, interlayers of RoomT-KBi are devoid of $\mathrm{Mn}^{3+}$ cations and the layer charge deficit is compensated for by the sole presence of 0.30 interlayer $\mathrm{K}^{+}$cations. 
To provide local charge compensation, these cations should be close to the source of layer deficit of charge. Specifically, $\mathrm{O}_{\text {layer }}$ coordinated to $2 \mathrm{Mn}_{\text {layer }}$ and a vacant layer site are strongly undersaturated, ideally receiving only $2 \times 0.667=1.333 \mathrm{vu}$ (valence unit). Therefore, the location and distribution of $\mathrm{K}^{+}$cations is most likely related to the distribution of vacant sites so as to provide local charge compensation. The absence of super-reflections in both XRD and selected-area electron diffraction patterns (data not shown) suggest that vacant sites and associated interlayer $\mathrm{K}^{+}$cations are randomly distributed in $\mathrm{KBi}$.

\section{Crystal Chemistry of $\mathrm{KBi}$ from $100-250^{\circ} \mathrm{C}$}

DT-TG results show, in agreement with $\mathrm{XRD}$, that dehydration of $\mathrm{KBi}$ layers initiates at $\sim 90^{\circ} \mathrm{C}$ and is complete at $\sim 150^{\circ} \mathrm{C}$. Apart from the departure of the interlayer $\mathrm{H}_{2} \mathrm{O}$ molecules, which leads to the collapse of $\mathrm{KBi}$ layers, heating of $\mathrm{KBi}$ up to $250^{\circ} \mathrm{C}$ does not alter its basic structure, which can be indexed in the $R \overline{3} m$ space group ( $3 R^{-}$polytype) over this temperature range. The hexagonal symmetry of KBi layers is thus preserved and only a minor increase of unit-cell dimensions is observed, most likely as a result of thermal motion (Table 1 - Figure 4). Once $\mathrm{H}_{2} \mathrm{O}$ molecules have left the structure, the six-fold coordination of $\mathrm{K}^{+}$is likely ensured by the nearest six $\mathrm{O}_{\text {layer }}$ defining the interlayer prismatic cavity. As a result of the dehydration, interlayer $\mathrm{K}^{+}$cations thus slightly migrate from $(-0.24,0,0.167)$ at room temperature towards the center of the prism at $250^{\circ} \mathrm{C}[(-0.29,0,0.167)-$ Table 3$]$ most likely to provide more appropriate $\mathrm{K}-\mathrm{O}_{\text {layer }}$ distances after the partial layer collapse. In addition, the relative proportion of random stacking faults $\left(\mathrm{W}_{\mathrm{R}}\right)$ steadily increases (from 5-17\%) with increasing temperature in the well-crystallized phases, whereas the CSDS in the ab plane is decreasing from $300 \AA$ to $180 \AA$. In contrast, the CSDS along the $\mathbf{c}^{*}$ axis in the wellcrystallized phases remains unchanged with temperature (6 layers in average) and the relative proportion of the fine-grained quasi-turbostratic phase does not vary significantly with temperature (Table 3). 
Whereas $\mathrm{KBi}$ structure is stable up to $250^{\circ} \mathrm{C}$, significant chemical and structural

modifications occur when temperature reaches $350^{\circ} \mathrm{C}$. Specifically, modifications affecting unit-cell dimensions, Mn oxidation state and related weight loss reported in results section will be discussed below.

Evolution of Layer Dimensions and Mn Oxidation State. The temperature increase from $250^{\circ} \mathrm{C}$ to $350^{\circ} \mathrm{C}$ does not modify the layer symmetry. However, a significant increase of the layer unit-cell parameters is observed from $b=2.851 \AA$ at $250^{\circ} \mathrm{C}$ to $b=2.868 \AA$ and $2.885 \AA$ for the layers of the $3 R^{-}$phase and of the MLS, respectively. A significant weight loss (2.7 wt\% - Figure 2) also accompanies the temperature increase. As mentioned above, such dramatic increase of the unit-cell dimensions within the ab plane is likely not related to thermal motion but rather to the partial reduction of $\mathrm{Mn}^{4+}$ to $\mathrm{Mn}^{3+}$. Chemical analysis of $\mathrm{KBi}$ crystals after cooling indeed revealed a much lower Mn mean oxidation state (3.78 for sample AfterT-KBi vs 4.00 for sample RoomT-KBi). Partial reduction from $\mathrm{Mn}^{4+}$ to $\mathrm{Mn}^{3+}$ most likely account for the observed decrease which is likely due to the presence of $22 \%$ of $\mathrm{Mn}^{3+}$ cations in the heated sample. Herbstein et al. also observed a weight loss (3.7 wt\%) when heating a $\mathrm{K}_{0.5} \mathrm{Mn}_{0.875} \mathrm{O}_{2}$ sample to $\sim 500^{\circ} \mathrm{C}$ and associated this effect with an oxygen loss, which was in turn hypothesized to result from the partial reduction of $\mathrm{Mn}^{4+}$ to $\mathrm{Mn}^{3+}$. 57,68 Because $<\mathrm{Mn}-\mathrm{O}>$ distances are longer for $\mathrm{Mn}^{3+}(2.04 \AA)$ than for $\mathrm{Mn}^{4+}$ cations (1.912 $\AA$ ), the presence of such a high amount of $\mathrm{Mn}^{3+}$ in $\mathrm{KBi}$ layers is responsible for the significant increase of the unit-cell dimensions within the ab plane.

The hexagonal layer symmetry may at first sight seem to contradict the presence of $\mathrm{Mn}^{3+}$ cations in the layer. $\mathrm{Mn}^{3+}$ cations are known to be affected by the Jahn-Teller effect that lowers the symmetry of the 3d electron orbitals and distorts the octahedra leading to 4 short and 2 long Mn-O distances. To minimize the resulting steric strains in $\mathrm{Mn}^{3+}$-rich birnessites, $\mathrm{Mn}^{3+}$-octahedra distorted by the Jahn-Teller effect are commonly segregated in $\mathrm{Mn}^{3+}$-rich rows parallel to the $\mathbf{b}$ axis and are systematically oriented with their long Mn-O bonds (2.26 $\AA$ 
in crednerite) ${ }^{86}$ along the a axis giving rise to an orthogonal layer symmetry. This cooperative Jahn-Teller effect was reported for $\mathrm{Na}$ - and Ca-birnessite varieties obtained from the oxidation of $\mathrm{Mn}^{2+}$, $5,77,95$ and for a K-birnessite variety obtained from reduction of $\mathrm{Mn}^{7+}$ at $1000^{\circ} \mathrm{C}^{84}$ In absence of cooperative Jahn-Teller effect the long $\mathrm{Mn}-\mathrm{O}$ bonds of $\mathrm{Mn}^{3+}$ octahedra are randomly oriented at $\pm n 120^{\circ}$ ( $n$ integer) with respect to the a axis. In this case, the hexagonal symmetry of the layers is preserved, but the resulting increase of the average octahedron size increases the unit-cell $b$ parameter as compared to phyllomanganate varieties that are devoid of $\mathrm{Mn}^{3+}$ cations. Such a hexagonal layer symmetry with large unit-cell $b$ parameter (2.925 $\AA$ ) have been reported for lithiophorite whose layers contain 33\% of $\mathrm{Mn}^{3+}$ octahedra. $^{94}$

For sample $350-\mathrm{KBi}$, the unfavorable presence of strains in the layers is likely compensated for by the thermal energy available at $350^{\circ} \mathrm{C}$. The proposed model is supported by the experimental results obtained by Gaillot et al. for a $\mathrm{KBi}$ sample obtained from the thermal decomposition of $\mathrm{KMnO}_{4}$ at $1000^{\circ} \mathrm{C} \quad\left(\mathrm{KBi}_{100}\right){ }^{84}$ This sample has a $\mathrm{Mn}_{0.737}^{4+} \mathrm{Mn}_{0.246}^{3+} \square_{0.017}$ layer cation composition, orthogonal layer symmetry with $a=5.155 \AA$, $b=2.846 \AA, a / b=1.811$, and exhibits an ordered distribution of $\mathrm{Mn}^{3+}$ - and $\mathrm{Mn}^{4+}$-octahedra in its layers. The layer symmetry of $\mathrm{KBi}_{100}$ sample becomes hexagonal with an increase of the unit-cell $b$ parameter to $2.895 \AA$ when heated in situ to $350^{\circ} \mathrm{C}$, in relation with the redistribution of distorted $\mathrm{Mn}^{3+}$-octahedra orientations at $\pm n 120^{\circ}$ ( $n$ integer) with respect to the a axis with equal probability for all three possible values of $n$. The abrupt increase of the unit-cell parameter $b$ for sample 350-KBi can thus be considered as additional evidence for the presence of a significant amount of $\mathrm{Mn}^{3+}$ octahedra in 350-KBi layers, and for the partial reduction of $\mathrm{Mn}^{4+}$ to $\mathrm{Mn}^{3+}$ at $350^{\circ} \mathrm{C}$.

Loss of Weight and Associated Structural Transformation of the Layer (Loss of $O_{\text {layer }}$ and Migration of Vacant Layer Sites). Together with the formation of layer $\mathrm{Mn}^{3+}$ cations and with the associated increase of the unit-cell $a$ and $b$ parameters, the temperature increase up to 
$350^{\circ} \mathrm{C}$ induces a $2.7 \%$ weight loss over the $250-400^{\circ} \mathrm{C}$ range. This weight loss likely results from the migration of vacant layer octahedra and from the induced formation of vacancy-free layers. A significant temperature increase can indeed allow the migration of $\mathrm{Mn}_{\text {layer }}$ to the nearest vacant sites forming new vacant sites. Consistently, sample AfterT-KBi, whose layers are essentially devoid of vacant sites, exhibits a weight gain rather than a weight loss over the $250-400^{\circ} \mathrm{C}$ range (Figure $2 \mathrm{~b}$ ). Similar process of cation migration within octahedral layers has been described for example in 2:1 phyllosilicates. During the dehydroxylation of $\mathrm{Fe}^{3+}$ and $\mathrm{Mg}^{2+}$-rich dioctahedral micas, which occurs at $\sim 450-600^{\circ} \mathrm{C}$, octahedral $\mathrm{Fe}^{3+}$ and $\mathrm{Mg}^{2+}$ cations migrate within the layer to the adjacent vacant octahedron to restore the structure stability which was disturbed following dehydroxylation. ${ }^{96,97,98}$ Cation migration has also been described when octahedral $\mathrm{Fe}^{3+}$ is reduced in 2:1 phyllosilicates. ${ }^{24}$ In KBi layers, cation migration may result either in the migration of vacant sites to crystal edges or in the formation of vacancy clusters. In both cases, migration of vacant layer sites results in the reduction of the amount of vacant layer sites and in the loss of $\mathrm{O}_{\text {layer }}$.

Loss of $\mathrm{O}_{\text {layer }}$ was shown to occur during the thermal reduction of synthetic pyrolusite $\left(\mathrm{MnO}_{2}\right)$ in situ between $300^{\circ} \mathrm{C}$ and $500^{\circ} \mathrm{C} .^{82}$ Using Electron Energy Loss Spectroscopy analysis, these authors were able to follow the reduction of Mn as a function of temperature by simultaneously determining the valence state of $\mathrm{Mn}$ and quantifying the relative proportion of oxygen vacancies created. In their study, Wang et al. found that reduction of $\mathrm{MnO}_{2}$ occurs between $300-400^{\circ} \mathrm{C}$ with no visible structural change. However, they identified

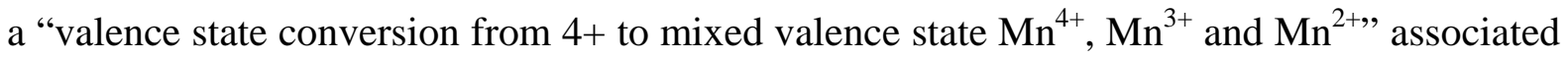
with a decrease of the O/Mn ratio from 2.00 to 1.64 (values taken from Figure 4 in Wang et al.). ${ }^{82}$ For our $\mathrm{KBi}$ sample, the extent of $\mathrm{O}_{\text {layer }}$ loss can be estimated theoretically from the modification of KBi structural formula induced by the heating. Transformation from sample Room-KBi (structural formula $\mathrm{K}_{0.30}^{+}\left(\mathrm{Mn}_{0.925}^{4+} \square_{0.075}\right) \mathrm{O}_{2}-$ eq 2 ) to sample 350-KBi leads to a $\mathrm{K}_{0.30}^{+}\left(\mathrm{Mn}_{0.625}^{4+} \mathrm{Mn}_{0.300}^{3+}\right) \mathrm{O}_{1.85}$ structural formula for the latter vacancy-free layers. As a result the 
theoretical weight loss associated to the departure of $\mathrm{O}_{\text {layer }}$ is $\sim 2.5 \mathrm{wt} \%$, in agreement with that experimentally determined (2.7 wt\%). The structural formula proposed for the vacancyfree layers of sample $350-\mathrm{KBi}$ can thus be transformed to $\mathrm{K}_{0.324}^{+}\left(\mathrm{Mn}_{0.676}^{4+} \mathrm{Mn}_{0.324}^{3+}\right) \mathrm{O}_{2}$. A similar agreement between calculated (4.0\%) and experimentally determined (3.7\%) weight loss corresponding to the departure of $\mathrm{O}_{\text {layer }}$ is obtained for the sample studied by Herbstein et al. using the structural formulae reported for their initial $\left(\mathrm{K}_{0.50}^{+}\left(\mathrm{Mn}_{0.875}^{4+} \square_{0.125}\right) \mathrm{O}_{2}\right)$ and heattreated $\left(\mathrm{K}_{0.50}^{+}\left(\mathrm{Mn}_{0.375}^{4+} \mathrm{Mn}_{0.50}^{3+}\right) \mathrm{O}_{1.75}\right)$ specimens. ${ }^{68}$

In conclusion, the weight loss observed over the $250-400^{\circ} \mathrm{C}$ temperature range for synthetic birnessites may be considered as an evidence for the presence of vacant layer sites in the sample at room temperature. In the present case, the weight loss results from the thermally induced migration of the vacant sites from the structure to the edges of the layers, thus inducing their vanishing and the associated loss of $\mathrm{O}_{\text {layer }}$. Note that over the same temperature range weight loss can be alternatively related to the dehydroxylation of birnessite, as described for high-temperature $\mathrm{KBi}$ obtained at $800^{\circ} \mathrm{C}$. \{Gaillot, $2003 \# 2889$ \}. In this case, the weight loss results from the departure of $\mathrm{OH}^{-}$groups initially bond to preexisting $\mathrm{Mn}^{3+}$ cations located in the interlayer region, above or below the layer vacant sites, rather than in the octahedral layer.

Layer Stacking Mode and Interlayer Structure. In addition to the above structural modifications, heating of $\mathrm{KBi}$ sample from $250^{\circ} \mathrm{C}$ to $350^{\circ} \mathrm{C}$ is accompanied by a strong decrease of structural order and by a modification of the layer stacking for part of the layers. Simulation of 350-KBi XRD pattern shows indeed that the main well-crystallized phase keeps the initial $3 R^{-}$stacking sequence in which adjacent layers are shifted with respect to each other by $-a / 3$ along the a axis. In contrast, in the accessory MLS phase $70 \%$ of the layers (B layers) are shifted by $+a / 3$ along the a axis ( $3 R^{+}$stacking sequence). These layers are randomly interstratified with layers that kept their initial $3 R^{-}$polytype (A layers). This layer stacking modification is likely related to the increased amount of $\mathrm{Mn}^{3+}$ in the octahedral 
layers and to the associated decreased amount of vacant layer sites. At room temperature, half of interlayer $\mathrm{K}^{+}$cations are most likely located above the empty layer tridentate cavity of the lower layer and below a layer vacant octahedral of the upper one (or vice versa, $\mathrm{AbC}_{\mathrm{b}^{\prime}}^{\mathrm{a}} \mathrm{CaB}$... stacking sequence - Figure 6). At $350^{\circ} \mathrm{C}$, the proportion of vacant layers sites is strongly decreased and in A layers interlayer $\mathrm{K}^{+}$cations are systematically facing an occupied $\mathrm{Mn}$ octahedron on one side of the interlayer. The resulting K-Mn repulsion could destabilize the layer stacking. By contrast, the initial prismatic coordination of interlayer $\mathrm{K}^{+}$observed in $\mathrm{A}$ layers is modified in B layers to become octahedral ( $\mathrm{AbC}_{\mathrm{b}}{ }^{\prime} \mathrm{A}^{,}{ }^{\mathrm{A}} \mathrm{C}^{\prime} \mathrm{BcA} \mathrm{A} . .-$ Figure 10). The latter coordination seems more favorable as interlayer $\mathrm{K}^{+}$cations are located above and below empty tridentate cavities of the two adjacent layers, the K-Mn repulsion being then screened by $\mathrm{O}_{\text {layer }}$ This interlayer configuration would allow a higher content of layer $\mathrm{Mn}^{3+}$ and a lower vacant site content in layers of $3 R^{+}$fragments, and would explain the larger unitcell parameters of the layers in the accessory MLS as compared to those of layers making up the $3 R^{-}$main phase ( $b=2.885 \AA$ and $2.868 \AA$, respectively)

Degree of Crystallinity and Structural Order of 350-KBi. The CSDS within the ab plane of both the main $3 R^{-}$phase and of the MLS are slightly increased as compared to that of the main 250-KBi phase (200-230 $\AA$ vs $180 \AA$, respectively - Table 3). This difference is likely due to the dramatic rearrangement of layer cations resulting from the partial reduction of $\mathrm{Mn}^{4+}$ to $\mathrm{Mn}^{3+}$ and from the subsequent migration of vacant layer octahedra. On the other hand, the proportion of random stacking faults is very high in the main well-crystallized $3 R^{-}$ phase $\left(\mathrm{W}_{\mathrm{R}}=30 \%\right)$, most likely as the result of the unfavorable direct repulsion between interlayer $\mathrm{K}^{+}$cations and $\mathrm{Mn}_{\text {layer }}$ ones induced by the evolution of $\mathrm{KBi}$ crystal-chemistry occurring at this temperature.

Structural Transformation of $\mathbf{3 5 0 - K B i}$ into AfterT-KBi. Comparison of the phase composition and structure in 350-KBi and AfterT-KBi samples allows proposing a structural mechanism for the phase transformation occurring when sample $350-\mathrm{KBi}$ is cooled down to 
obtain sample AfterT-KBi. Indeed, the relative proportion of the main well-crystallized $3 R^{-}$ phase in sample $350-\mathrm{KBi}(40 \%)$ is similar to that of the proportion of the $1 \mathrm{M} / 3 R^{-} \mathrm{MLS}$ in sample AfterT-KBi (50\%). To ease the following discussion, dehydrated $3 R^{-}$polytype in sample $350-\mathrm{KBi}$ and hydrated $3 R^{-}$polytype in sample AfterT-KBi will be hereafter referred to as $3 R_{\mathrm{d}}^{-}$and $3 R_{\mathrm{h}}^{-}$, respectively. It is likely that during this transition the $3 R_{\mathrm{d}}^{-}$is transformed into the $1 M$ structure (with $10 \%$ residual $3 R_{\mathrm{h}}^{-}$) whereas the accessory $3 R_{\mathrm{d}}^{+} / 3 R_{\mathrm{d}}^{-}$MLS (ratio 70:30) from sample 350-KBi will contribute to the quasi-turbostratic phase which contains $3 R_{\mathrm{h}}^{-}$and $1 M$ fragments (4:1 ratio) in sample AfterT-KBi.

Origin of $1 M$ Layers. Because of its prevalence, the transition from the $3 R_{\mathrm{d}}^{-}$polytype to the $1 M$ polytype will be considered first. As mentioned above, the new-formed $\mathrm{Mn}^{3+}$ octahedra in the $3 R_{\mathrm{d}}^{-}$structure have a random orientation of their long $\mathrm{Mn}^{3+}-\mathrm{O}$ bonds relative to the a axis $\left( \pm n 120^{\circ}\right)$ thus inducing significant lattice strains in the layers. Besides, interlayer $\mathrm{K}^{+}$cations are shifted towards the center of interlayer prismatic cavities to ensure proper bond lengths with closest $\mathrm{O}_{\text {layer }}$ from adjacent layers. This shift, along with the absence of vacant layer sites and the interlayer collapse due to dehydration, significantly increase the repulsion between interlayer $\mathrm{K}^{+}$and $\mathrm{Mn}_{\text {layer }}$. At $350^{\circ} \mathrm{C}$, the effect of these structural features unfavorable to layer stability is compensated for by thermal energy. Logically, when lowering the temperature, stabilization of the resulting $1 M$ structure will ideally lead to the minimization of lattice strains and $\mathrm{K}^{+}-\mathrm{Mn}_{\text {layer }}$ interactions. In addition, rehydration of $1 M$ interlayers should be accompanied by the formation of appropriate $\mathrm{K}^{+}-\mathrm{H}_{2} \mathrm{O}$ and $\mathrm{H}_{2} \mathrm{O}-\mathrm{O}_{\text {layer }}$ bond lengths so as to provide local charge compensation and to contribute to the cohesion between adjacent layers. These different aspects of AfterT-KBi structure will be discussed hereafter for the main $1 M / 3 R_{\mathrm{h}}^{-}$phase.

From chemical analysis, sample AfterT-KBi contains $~ 22 \%$ of the $\mathrm{Mn}^{3+}$ (structural formula - eq 3), and both the orthogonal symmetry of the layers in the $1 M$ polytype (Table 1 ) and the structure model determined (Table 3) suggest that these cations are actually located in 
the octahedral layer. The presence of a significant amount of $\mathrm{Mn}^{3+}$ cations in vacancy-free layers indeed leads, at room temperature, to the departure from the hexagonal layer symmetry because of cooperative Jahn-Teller effect. The transformation of $3 R_{\mathrm{d}}^{-}$polytype to $1 M$ polytype is most likely accompanied by such re-orientation of the layer $\mathrm{Mn}^{3+}$-octahedra leading to a unique orientation of the long $\mathrm{Mn}^{3+}-\mathrm{O}$ bonds and thus giving rise to the orthogonal layer symmetry. Such systematic orientation along the a axis of the long $\mathrm{Mn}^{3+}-\mathrm{O}$ bonds of distorted octahedra minimizes strains in the layers as the four short $\mathrm{Mn}^{3+}-\mathrm{O}$ distances are similar to $<\mathrm{Mn}^{4+}$-O $>(1.93 \AA$ vs $1.91 \AA)$. For this reason unit-cell $b$ parameters are very similar (2.84-2.86 $\AA$ ) in all $\mathrm{Mn}^{3+}$-rich natural and synthetic varieties having orthogonal layer symmetry regardless of their layer $\mathrm{Mn}^{3+}$ content. ${ }^{69,75,77,83,84,95}$ In contrast, the unit-cell $a$ parameter strongly depends on this content and $a / b$ ratios vary significantly for such $\mathrm{Mn}^{3+}$-rich compounds. Values reported in the literature for $a / b$ ratio are 1.936 in crednerite $\left(\mathrm{CuMnO}_{2}, \mathrm{Mn}^{3+}=100 \%\right),{ }^{86} 1.830$ in Na-buserite $\left(\mathrm{NaBu}, \mathrm{Mn}^{3+}=33 \%, a=\right.$ $5.223 \AA, b=2.854 \AA),{ }^{75} 1.817 \AA$ in triclinic Na-birnessite $\left(\mathrm{NaBi}, \mathrm{Mn}^{3+}=30 \%, a=5.174 \AA\right.$, $b=2.848 \AA$ ), ${ }^{77,83}$ and 1.811 in K-rich birnessite obtained from the thermal decomposition of $\mathrm{KMnO}_{4}$ at $1000^{\circ} \mathrm{C}\left(\mathrm{KBi}_{100}, \mathrm{Mn}^{3+}=25 \%, a=5.155 \AA, b=2.846 \AA\right) .{ }^{84}$ In $1 M$ layers of sample AfterT-KBi, unit-cell $b$ parameter $(b=2.850 \AA)$ is consistent with literature data and $a / b$ ratio equals 1.800, which would correspond to $\sim 20 \%$ of $\mathrm{Mn}^{3+}$ in the layers. This value is consistent with the average oxidation state of Mn measured globally for sample AfterT-KBi (22\%).

Along with the re-orientation of distorted layer $\mathrm{Mn}^{3+}$-octahedra, the $3 R_{\mathrm{d}^{-}}^{-}$to- $1 M$ transformation during cooling is accompanied by modification of layer stacking, as the interlayer shift decreases from $-0.333 a$ to $-0.260 a(\Delta=+0.073 a)$. As the average CSDS along the $\mathbf{c}^{*}$ axis of both $350-\mathrm{KBi}$ and AfterT-KBi samples is equal to 6 layers, maximum displacement between layers of a given crystal induced by the layer stacking modification does not exceed $5 \Delta$, that is $\sim 1.5 \AA$, taking into account the variation of unit-cell parameters. This displacement is likely even smaller as hydration of the $3 R_{\mathrm{d}}^{-}$interlayers during cooling 
most likely starts simultaneously from both ends of crystals. These limited layers displacements are likely to require little energy to proceed.

In addition, mutual arrangement of layers in the $1 M$ polytype is favorable to the layer stacking stability as it allows for the formation of H-bonds and for the minimization of cation electrostatic repulsion. Each interlayer $\mathrm{K}^{+}$cation is indeed coordinated by the two nearest $\mathrm{O}_{\text {layer }}$ from adjacent layers (2.703-2.831 $\AA$ ) and by four (or even six) $\mathrm{H}_{2} \mathrm{O}$ molecules at 2.713$2.862 \AA$ (and $3.161 \AA$ ). $\mathrm{H}_{2} \mathrm{O}$ molecules are located at $2.616 \AA$ from the nearest $\mathrm{O}_{\text {layer, }}$ thus forming strong H-bonds (Figure 12). Finally, as compared to the $3 R_{\mathrm{h}}^{-}$phase, the $1 M$ layer stacking leads to an increased K-Mn distance thus decreasing the repulsion between these two cations (Figures 6 and 12).

Note that the main structural features of the $1 M$ phase are similar to those of the Ksaturated birnessite synthesized at high $\mathrm{pH}$ and room temperature from $\mathrm{Mn}^{2+}$ precursors. ${ }^{83} \mathrm{It}$ is likely that $3 R_{\mathrm{h}}^{-}$layer fragments $(10 \%)$ coexisting with the prevailing $1 M$ fragments are inherited from the initial $3 R_{\mathrm{d}}^{-}$structure of sample $350-\mathrm{KBi}$ in which the random orientation of the layer $\mathrm{Mn}^{3+}$ octahedral is maintained.

Origin of the $3 R_{\mathrm{h}}^{-}$Fragments in the Quasi-Turbostratic Phase. At first sight the hypothesized transition from the $3 R_{\mathrm{d}}^{+} / 3 R_{\mathrm{d}}^{-}$MLS into the poorly crystallized phase during cooling of sample 350-KBi appears unlikely as at least one of the stability unfavorable factors described for the $3 R_{\mathrm{d}}^{-}$polytype is absent in the $3 R_{\mathrm{d}}^{+}$one. In the $3 R_{\mathrm{d}}^{+}$phase each interlayer $\mathrm{K}^{+}$ cation is indeed octahedrally coordinated and located above/below empty tridentate cavities from the two neighboring layers (Figure 10). As a result, proper $\mathrm{K}-\mathrm{O}_{\text {layer }}$ bond lengths are obtained with closest $\mathrm{O}_{\text {layer }}$ from adjacent layers (Table 4), and direct interaction with the $M n_{\text {layer }}$ cations is avoided. After cooling of the $3 R_{\mathrm{d}}^{+} / 3 R_{\mathrm{d}}^{-}$adjacent layers in the hydrated phase could thus logically maintain the $+a / 3$ interlayer shift along the a axis to preserve such favorable disposition of layer and interlayer cations. In addition, this layer stacking mode would allow for the formation of strong $\mathrm{H}$-bonds between $\mathrm{O}_{\text {layer }}$ and $\mathrm{H}_{2} \mathrm{O}$ molecules if the 
latter were located between $\mathrm{O}_{\text {layer }}$ of adjacent layers in a position equivalent to $(0.167,0$, 0.167) (Figure 10). However, through $\mathrm{H}$-bonds neutral $\mathrm{H}_{2} \mathrm{O}$ molecules provide $\mathrm{O}_{\text {layer }}$ with positive charges and they should thus interact with interlayer cations to compensate for this transfer of charge. A careful analysis of the $3 R^{+}$interlayer space shows that the location of $\mathrm{K}^{+}$cations in the interlayer octahedral site is inconsistent with positions of $\mathrm{H}_{2} \mathrm{O}$ molecules allowing for $\mathrm{H}$-bond formation, $\mathrm{K}-\mathrm{H}_{2} \mathrm{O}$ distances being either too short or too long. As a consequence, hydration of the $3 R^{+}$phase following the cooling of sample $350-\mathrm{KBi}$ should involve a modification of the $3 R^{+}$stacking so that two conditions are satisfied. First, $\mathrm{H}_{2} \mathrm{O}$ molecules should form $\mathrm{H}$-bonds with adjacent $\mathrm{O}_{\text {layer }}$ and interact with interlayer $\mathrm{K}^{+}$cations. Second, interlayer $\mathrm{K}^{+}$cations should have appropriate coordination and proper $<\mathrm{K}-\mathrm{O}_{\text {layer }}>$ bond length.

As discussed above, these two conditions are satisfied in the $1 M$ phase. It is thus likely that $3 R_{\mathrm{d}}^{+}$fragments present in the $3 R_{\mathrm{d}}^{+} / 3 R_{\mathrm{d}}^{-}$MLS tend to transform into such $1 M$ fragments. However, thermal energy is likely not sufficient to allow a complete modification of the layer stacking from $+a / 3$ to $-0.260 a$ and random stacking faults in the quasi-turbostratic phase most likely result from displacements between adjacent layers intermediate between these two values. Thermal energy is not sufficient either to modify the hexagonal layer symmetry which is preserved in the quasi-turbostratic phase in spite of the unfavorable lattice constrains resulting from the presence of layer $\mathrm{Mn}^{3+}$ cations. Note also that the relative proportion of $3 R_{\mathrm{h}}^{-}$and $1 M$ fragments in the quasi-turbostratic phase (20\% and $5 \%$, respectively) is similar to that of the $3 R_{\mathrm{d}}^{-}$fragments (30\%), which have the "right" interlayer displacement, in the $3 R_{\mathrm{d}}^{+} / 3 R_{\mathrm{d}}^{-}$MLS in sample 350-KBi.

Interlayer structure of the $3 R_{\mathrm{h}}^{-}$phase in $\mathrm{KBi}$ sample after cooling is similar to that determined before thermal treatment. In both cases, interlayer $\mathrm{K}^{+}$cations are coordinated by four $\mathrm{O}_{\text {layer }}$ defining the faces of the prism and by two $\mathrm{H}_{2} \mathrm{O}$ molecules located in the interlayer mid-plane. These $\mathrm{H}_{2} \mathrm{O}$ molecules have appropriate distances both with the nearest $\mathrm{O}_{\text {layer }}$ from 
adjacent layers and with the nearest interlayer $\mathrm{K}^{+}$cations. The main difference between the $3 R_{\mathrm{h}}^{-}$phases in $\mathrm{KBi}$ samples before thermal treatment and after cooling arises from their respective layer cation composition. After cooling, layers of the $3 R_{\mathrm{h}}^{-}$phase are vacancy-free and interlayer $\mathrm{K}^{+}$cation are systematically located above or below $\mathrm{Mn}_{\text {layer }}$. As a result, $3 R_{\mathrm{h}}^{-}$ structural fragments in AfterT-KBi sample should be considered as metastable although electrostatic repulsion between the two cations is partly decreased by the shift of the interlayer $\mathrm{K}^{+}$cations from the center of the prismatic cavity towards its faces. Metastability of these fragments also comes from the presence of lattice strains originating from the random orientation of distorted $\mathrm{Mn}^{3+}$-octahedra in the layers.

Acknowledgments. VAD is grateful to the Environmental Geochemistry Group of the LGIT (Grenoble, France) and to the Russian Science Foundation for financial support. BL acknowledges financial support from INSU/Géomatériaux, and CNRS/PICS709 programs. The authors are grateful to Pr. Alain Plançon (IST - Orléans) for the availability and the modification of his XRD calculation program. Céline Boissard (Hydr'ASA - Poitiers), Martine Musso and Delphine Tisserand (LGIT - Grenoble), and Serge Nitsche (CRMCN Marseilles) are thanked for their technical support (DT-TG analyses, chemical analyses, and SEM images, respectively).

(1) Giovanoli, R.; Stähli, E; Feitknecht, W. Helv. Chim. Acta 1970, 53, 209-220.

(2) Giovanoli, R.; Stähli, E; Feitknecht, W. Helv. Chim. Acta 1970, 53, 453-464.

(3) Burns, R.G.; Burns, V.M. Phil Trans Roy Soc London A 1977, 286, 283-301.

(4) Glover, E.D. Amer. Mineral. 1977, 62, 278-285. 
771 (5) Chukhrov, F.V.; Gorschkov, A.I.; Rudnitskaya, E.S.; Sivtsov, A.V. Izv. Akad. Nauk

Geol. 1978, 9, 67-76.

(6) Burns, V.M.; Burns, R.G. Earth Planet. Sci. Lett. 1978, 39, 341-348.

(7) Golden, D.C.; Dixon, J.B.; Chen, C.C. Clays \& Clay Miner. 1986, 34, 511-520.

(8) Chukhrov, F.V.; Sakharov, B.A.; Gorshkov, A.I.; Drits, V.A.; Dikov, Yu.P. Int. Geol. Rev. 1985, 27, 1082-1088.

(9) Drits, V.A.; Petrova, V.V.; Gorshkov, A.I. Lithology and Raw Materials 1985, 3, 1739.

(10) Cornell, R.M.; Giovanoli, R. Clays \& Clay Miner. 1988, 36, 249-257.

(11) Manceau, A.; Lanson, B.; Schlegel, M. L.; Harge, J. C.; Musso, M.; Eybert Berard, L.; Hazemann, J. L.; Chateigner, D.; Lamble, G. M. Amer. J. Sci. 2000, 300, 289-343.

(12) Bilinski, H.; Giovanoli, R.; Usui, A.; Hanzel, D. Amer. Mineral. 2002, 87, 580-591.

(13) Rogers, T. D. S.; Hodkinson, R. A.; Cronan, D. S. Marine Georesources and Geotechnology 2001, 19, 245-268.

(14) McKeown, D. A.; Post, J. E. Amer. Mineral. 2001, 86, 701-713.

(15) Exon, N. F.; Raven, M. D.; De Carlo, E. H. Marine Georesources and Geotechnology 2002, 20, 275-297.

(16) Mote, T. I.; Becker, T. A.; Renne, P.; Brimhall, G. H. Econ. Geol. Bull. Soc. Econ. Geol. 2001, 96, 351-366.

(17) Morozov, A. A.; Novikov, G. V.; Kulikova, L. N. Geochemistry International 2001, 39, 764-779.

(18) Manceau, A.; Tamura, N.; Celestre, R. S.; MacDowell, A. A.; Geoffroy, N.; Sposito, G.; Padmore, H. A. Environ. Sci. Technol. 2003, 37, 75-80.

(19) Vaniman, D. T.; Chipera, S. J.; Bish, D. L.; Duff, M. C.; Hunter, D. B. Geochim. Cosmochim. Acta 2002, 66, 1349-1374.

(20) Chao, T. T.; Theobald, P. K. Econ. Geol. 1976, 71, 1560-1569. 
(21) Manceau, A.; Drits, V.A.; Silvester, E.J.; Bartoli, C.; Lanson, B. Amer. Mineral. 1997, 82, 1150-1175.

(22) Manceau, A.; Schlegel, M. L.; Chateigner, D.; Lanson, B.; Bartoli, C.; Gates, W. P. In Synchrotron X-ray methods in clay science; Schulze, D. G., Stucki, J. W., Bertsch, P. M., Eds.; Clay Minerals Society: Boulder, Co, 1999; Clay Miner. Soc. Workshop Lectures Vol. 9, pp 68-114.

(23) Manceau, A.; Lanson, B.; Drits, V. A.; Chateigner, D.; Gates, W. P.; Wu, J.; Huo, D.; Stucki, J. W. Amer. Mineral. 2000, 85, 133-152.

(24) Manceau, A.; Drits, V. A.; Lanson, B.; Chateigner, D.; Wu, J.; Huo, D.; Gates, W. P.; Stucki, J. W. Amer. Mineral. 2000, 85, 153-172.

(25) Taylor, R.M.; McKenzie, R.M.; Norrish, K. Aust. J. Soil Res. 1964, 2, 235-248.

(26) McKenzie, R.M. Aust. J. Soil Res. 1967, 5, 235-246.

(27) McKenzie, R.M. Aust. J. Soil Res. 1980, 18, 61-73.

(28) Kim, J. G.; Dixon, J. B.; Chusuei, C. C.; Deng, Y. J. Soil Sci. Soc. Am. J. 2002, 66, 306-315.

(29) Cheney, M. A.; Shin, J. Y.; Crowley, D. E.; Alvey, S.; Malengreau, N.; Sposito, G. Colloid Surface A 1998, 137, 267-273.

(30) Mench, M. J.; Manceau, A.; Vangronsveld, J.; Clijsters, H.; Mocquot, B. Agronomie 2000, 20, 383-397.

(31) McBride, M. B.; Martinez, C. E. Environ. Sci. Technol. 2000, 34, 4386-4391.

(32) Healy, T.W.; Herring, A.P.; Fuerstenau, D.W. J. Colloid Interface Sci. 1966, 21, 435444.

(33) Balistrieri, L.S.; Murray, J.W. Geochim. Cosmochim. Acta 1982, 46, 1041-1052.

(34) Gray, MJ; Malati, MA. J. Chem. Technol. Biotechnol. 1979, 29, 127-134.

(35) Stumm, W. Chemistry of the solid-water interface and particle-water interface in natural systems; Wiley: New York, 1992. 
(36) Le Goff, P.; Baffier, N.; Bach, S.; Pereira-Ramos, J-P. Mat. Res. Bull. 1996, 31, 6375.

(37) Tu, S.; Racz, G.J.; Goh, T.B. Clays \& Clay Miner. 1994, 42, 321-330.

(38) Paterson, E.; Swaffield, R.; Clark, L. Clay Miner. 1994, 29, 215-222.

(39) Novikov, G. V.; Cherkashev, G. A. Geochemistry International 2000, 38 Suppl. 2, S194-S205.

(40) Dyer, A.; Pillinger, M.; Harjula, R.; Amin, S. J. Mater. Chem. 2000, 10, 1867-1874.

(41) Naidja, A.; Liu, C.; Huang, P. M. J. Colloid Interface Sci. 2002, 251, 46-56.

(42) Gray, MJ; Malati, MA. J. Chem. Technol. Biotechnol. 1979, 29, 135-144.

(43) Catts, J.G.; Langmuir, D. Appl. Geochem. 1986, 1, 255-264.

(44) Ran, Y.; Fu, J. M.; Rate, A. W.; Gilkes, R. J. Chem. Geol. 2002, 185, 33-49.

(45) Manceau, A.; Gorshkov, A.I.; Drits, V.A. Amer. Mineral. 1992, 77, 1144-1157.

(46) Manceau, A.; Gorshkov, A.I.; Drits, V.A. Amer. Mineral. 1992, 77, 1133-1143.

(47) Silvester, E.J.; Manceau, A.; Drits, V.A. Amer. Mineral. 1997, 82, 962-978.

(48) Manceau, A.; Charlet, L. J. Colloid Interface Sci. 1992, 148, 425-442.

(49) Stone, A.T.; Godtfredsen, K.L.; Deng, B. In Chemistry of aquatic systems: Local and global perspectives; Bidoglio, G., Stumm, W., Eds.; ECSC, EEC, EAEC: Brussels, 1994, pp 337-374.

(50) Guha, H.; Saiers, J. E.; Brooks, S.; Jardine, P.; Jayachandran, K. Journal of Contaminant Hydrology 2001, 49, 311-334.

(51) Tournassat, C.; Charlet, L.; Bosbach, D.; Manceau, A. Environ. Sci. Technol. 2002, 36, 493-500.

(52) Petrie, R. A.; Grossl, P. R.; Sims, R. C. Environ. Sci. Technol. 2002, 36, 3744-3748.

(53) Manning, B. A.; Fendorf, S. E.; Bostick, B.; Suarez, D. L. Environ. Sci. Technol. 2002, 36, 976-981.

(54) Banerjee, D.; Nesbitt, H. W. Geochim. Cosmochim. Acta 1999, 63, 1671-1687. 
(55) Kim, S. H.; Im, W. M.; Hong, J. K.; Oh, S. M. J. Electrochem. Soc. 2000, 147, 413419.

(56) Feng, Q; Kanoh, H; Miyai, Y; Ooi, K. Chem. Mater. 1995, 7, 1226-1232.

(57) Chen, R.J.; Zavalij, P; Whittingham, M.S. Chem. Mater. 1996, 8, 1275-1280.

(58) Chen, R.J.; Chirayil, T.; Zavalij, P.; Whittingham, M.S. Solid State Ionics 1996, 86$88,1-7$.

(59) Bach, S; Henry, M; Baffier, N; Livage, J. J. Solid State Chem. 1990, 88, 325-333.

(60) Bach, S; Pereira-Ramos, J-P; Bafier, N. Electrochim. Acta 1993, 38, 1695-1698.

(61) Le Goff, P; Baffier, N; Bach, S; Pereira-Ramos, J-P. J. Mater. Chem. 1994, 4, 875881.

(62) Ching, S.; Landrigan, J.A.; Jorgensen, M.L.; Duan, N.; Suib, S.L.; O'Young, C.L. Chem. Mater. 1995, 7, 1604-1606.

(63) Ching, S; Petrovay, D J; Jorgensen, M L; Suib, S L. Inorg. Chem. 1997, 36, 883-890.

(64) Cho, J; Kim, G B; Lim, H S; Kim, C-S; Yoo, S-I. Electrochemical and Solid-State Letters 1999, 2, 607-609.

(65) Tsuji, M.; Komarneni, S.; Tamaura, Y.; Abe, M. Mat. Res. Bull. 1992, 27, 741-751.

(66) Leroux, F; Guyomard, D; Piffard, Y. Solid State Ionics 1995, 80, 299-306.

(67) McKenzie, R.M. Miner. Mag. 1971, 38, 493-502.

(68) Herbstein, H.F.; Ron, G.; Weissman, A. J. Chem. Soc. (A) 1971, 1821-1826.

(69) Kim, S. H.; Kim, S. J.; Oh, S. M. Chem. Mater. 1999, 11, 557-563.

(70) Gaillot, A. C.; Flot, D.; Drits, V. A.; Manceau, A.; Burghammer, M.; Lanson, B. Chem. Mater. 2003, 15, 4666-4678.

(71) Gaillot, A-C; Lanson, Bruno.; Drits, V A. Chem. Mater. 2005, in preparation.

(72) Vetter, K J; Jaeger, N. Electrochim. Acta 1966, 11, 401-419.

(73) Lingane, J J; Karplus, R. Ind. Eng. Chem. Anal. Ed. 1946, 18, 191-194. 
(74) Drits, V.A.; Tchoubar, C. X-ray diffraction by disordered lamellar structures: Theory and applications to microdivided silicates and carbons; Springer-Verlag: Berlin, 1990.

(75) Drits, V. A.; Lanson, B.; Gorshkov, A. I.; Manceau, A. Amer. Mineral. 1998, 83, 97118.

(76) Lanson, B.; Drits, V.A.; Silvester, E.J.; Manceau, A. Amer. Mineral. 2000, 85, 826838.

(77) Lanson, B.; Drits, V. A.; Feng, Q.; Manceau, A. Amer. Mineral. 2002, 87, 1662-1671.

(78) Lanson, B.; Drits, V. A.; Gaillot, A. C.; Silvester, E.; Plancon, A.; Manceau, A. Amer. Mineral. 2002, 87, 1631-1645.

(79) Gaillot, A. C.; Drits, V. A.; Plancon, A.; Lanson, B. Chem. Mater. 2004, 16, 1890 1905.

(80) Plançon, A., Ph. D. Thesis, Orléans, France, 1976.

(81) Plançon, A. J. Appl. Cryst. 2002, 35, 377.

(82) Wang, Z L; Yin, J S; Jiang, Y D. Micron 2000, 31, 571-580.

(83) Post, J.E.; Veblen, D.R. Amer. Mineral. 1990, 75, 477-489.

(84) Gaillot, A.-C.; Drits, V.A.; Lanson, B.; Manceau, A. Chem. Mater. 2005, In preparation.

(85) Thackeray, M.M.; de Kock, A.; David, W.I.F. Mat. Res. Bull. 1993, 28, 1041-1049.

(86) Töpfer, J.; Trari, M.; Gravereau, P.; Chaminade, J.P.; Doumerc, J.P. Z. Kristallogr. 1995, 210, 184-187.

(87) Shannon, R.D.; Gumeman, P.S.; Chenavas, J. Amer. Mineral. 1975, 60, 714-716.

(88) Glasser, L.S.D.; Ingram, L. Acta Crystallogr. 1968, B24, 1233-1236.

(89) Dachs, H. Z. Kristallogr. 1963, 118, 303-326.

(90) Drits, V.A.; McCarty, D.K. Amer. Mineral. 1996, 81, 852-863.

(91) Drits, V.A.; Varaxina, T.V.; Sakharov, B.A.; Plançon, A. Clays \& Clay Miner. 1994, 42, 382-390. 
(92) Méring, J. Acta Crystallogr. 1949, 2, 371-377.

(93) Villalobos, M.; Lanson, B.; Manceau, A.; Toner, B.; Sposito, G. Amer. Mineral. 2005, submitted.

(94) Post, J.E.; Appleman, D.E. Amer. Mineral. 1988, 73, 1401-1404.

(95) Drits, V.A.; Silvester, E.J.; Gorshkov, A.I.; Manceau, A. Amer. Mineral. 1997, 82, 946-961.

(96) Muller, F.; Drits, V. A.; Plancon, A.; Besson, G. Clay Miner. 2000, 35, 491-504.

(97) Muller, F.; Drits, V. A.; Tsipursky, S. I.; Plancon, A. Clay Miner. 2000, 35, 505-514.

(98) Muller, F.; Drits, V.; Plancon, A.; Robert, J. L. Clays \& Clay Miner. 2000, 48, 572585.

\section{Figure captions}

Figure 1. Scanning electron micrographs of KBi particles

Figure 2. Experimental TD-TG and DSC curves obtained for samples RoomT-KBi (a) and AfterT-KBi (b). The different endothermal peaks corresponding to successive loss of weight occur at $\sim 90^{\circ} \mathrm{C}, \sim 140^{\circ} \mathrm{C}, 250-400^{\circ} \mathrm{C}$, and $\sim 890^{\circ} \mathrm{C}$ and are labeled a, b, c, and d, respectively for sample RoomT-KBi. For sample AfterT-KBi a weight gain rather than a weight loss is observed over the $250-400^{\circ} \mathrm{C}$ temperature interval.

Figure 3. Experimental powder XRD pattern obtained for KBi samples. (a) Pattern recorded at room temperature (sample RoomT-KBi). (b) to (e) Patterns recorded in situ at $100^{\circ} \mathrm{C}$, $150^{\circ} \mathrm{C}, 250^{\circ} \mathrm{C}$ and $350^{\circ} \mathrm{C}$ (samples $100-, 150-, 250-$ and $350-\mathrm{KBi}$, respectively. (f) Pattern recorded after the complete thermal treatment up to $350^{\circ} \mathrm{C}$ and subsequent cooling to room temperature (sample AfterT-KBi). 
Figure 4. Evolution of unit-cell parameters for KBi samples as a function of temperature. The solid and dashed lines outline the variation of unit-cell parameters in the main ordered structure, and in the accessory structures, respectively.

Figure 5. (a) Comparison of calculated XRD patterns corresponding to the $3 R^{+}$(solid line) and $3 R^{-}$(crosses) polytypes. (b) to (d) Comparison between experimental (crosses) and calculated (solid line) XRD patterns for sample RoomT-KBi. (b) Calculation performed assuming a periodic $3 R^{-}$polytype $\left(R_{\mathrm{wp}}=15.77 \%\right)$. Arrows indicate the misfits at peak tails. (c) Calculation performed assuming a quasi-turbostratic phase with small coherent scattering domain size. (d) Optimum model. The calculated pattern is the sum of the periodic $3 R^{-}$ polytype and of the quasi-turbostratic phase $\left(R_{\mathrm{wp}}=9.55 \%\right)$.

Figure 6. Structure model for the $3 R^{-}$polytype. (a) Projection on the ab plane. The upper surface of the lower layer is shown as light shaded triangles whereas the lower surface of the upper layer is shown as dark shaded triangles. $\mathrm{Mn}_{\text {layer }}$ and $\mathrm{O}_{\text {layer }}$ of the two layers are shown as small and big solid circles, respectively. Large shaded circles represent interlayer $\mathrm{K}^{+}$. Position 1 corresponds to the faces of the interlayer prism defined by two empty tridentate layer cavities, whereas position 2 corresponds to the center of this prism. Position 3 corresponds to the optimum model. Open circles with a dashed outline (position 4) represent $\mathrm{H}_{2} \mathrm{O}$ molecules. Dot-dashed lines outline the coordination polyhedron of interlayer $\mathrm{K}^{+}$cations which includes $4 \mathrm{O}_{\text {layer }}$ and $2 \mathrm{H}_{2} \mathrm{O}$ molecules. (b) Projection along the b axis. Open and solid symbols indicate atoms at $y=0$ and $y= \pm 1 / 2$, respectively. Large circles represent $\mathrm{O}_{\text {layer }}$ atoms, small circles represent $\mathrm{Mn}_{\text {layer, }}$ atoms, and squares represent vacant layer octahedra. Dotdashed lines outline the interlayer prisms defined by two empty tridentate layer cavities. The center of these prisms is shown by regular dashed lines. Other patterns as in Figure 6a.

Figure 7. Comparison between experimental (crosses) and calculated (lines) XRD patterns for sample RoomT-KBi. Comparison is shown for $20 \ell / 11 \ell$ reflections (a) and for $31 \ell / 02 \ell$ ones (b). Dot-dashed and dashed lines correspond to calculations performed assuming 
950 interlayer $\mathrm{K}^{+}$cations on the faces (position 1 in Figure 6) or in the center (position 2 in Figure

6) of the interlayer prism, respectively. The solid line corresponds to the calculation performed with the optimum position of interlayer $\mathrm{K}^{+}$cations (position 3 in Figure 6).

Figure 8. Comparison between experimental (crosses) and calculated (solid line) XRD patterns for KBi samples. (a) Sample 100-KBi. Calculation performed for a periodic hydrated $3 R^{-}$polytype $\left(\mathrm{R}_{\mathrm{wp}}=18.59 \%\right)$. (b) Sample $100-\mathrm{KBi}$. Calculation performed for a mixed-layer structure in which $70 \%$ of the layers are dehydrated. (c) Sample 100-KBi. Optimum model. The calculated pattern is the sum of a periodic hydrated $3 R^{-}$polytype, of a mixed-layer structure in which $70 \%$ of the layers are dehydrated and of a quasi-turbostratic phase $\left(R_{\mathrm{wp}}=\right.$ 12.24\%). (d) Sample 150-KBi. Optimum model. The calculated pattern is the sum of a periodic dehydrated $3 R^{-}$polytype and of a quasi-turbostratic phase $\left(R_{\mathrm{wp}}=8.92 \%\right)$. (e) Sample 250-KBi Optimum model. The calculated pattern is the sum of a periodic dehydrated $3 R^{-}$ polytype and of a quasi-turbostratic phase $\left(R_{\mathrm{wp}}=9.97 \%\right)$

Figure 9. Comparison between experimental (crosses) and calculated (solid line) XRD patterns for sample $350-\mathrm{KBi}$. (a) Calculation performed for a periodic $3 R^{-}$polytype. (b) Calculation performed for a mixed-layer structure containing $30 \%$ of layers shifted by $-a / 3$ along the $\mathbf{a}$ axis ( $3 R^{-}$fragments) and $70 \%$ of layers shifted by $+a / 3$ along the a axis (3R fragments). (c) Optimum model. The calculated pattern is the sum of a quasi-periodic $3 R^{-}$ structure of the above $3 R^{-} / 3 R^{+}$mixed-layer structure, and of a quasi-turbostratic structure $\left(R_{\mathrm{wp}}=9.92 \%\right)$.

Figure 10. Structure model for the $3 R^{+}$polytype (a) Projection on the ab plane. (b) Projection along the $\mathbf{b}$ axis. Patterns as in Figure 6.

Figure 11. Comparison between experimental (crosses) and calculated (solid line) XRD patterns for sample AfterT-KBi. (a) Calculation performed for a mixed-layer structure containing $1 M$ and $3 R^{-}$structural fragments (90:10 ratio $\left.-R_{\mathrm{wp}}=23.03 \%\right)$. (b) Calculation performed for a quasi-turbostratic phase containing $3 R^{-}$and $1 M$ structural fragments. (c) 
976 Optimum model. The calculated pattern is the sum of the $1 M / 3 R^{-}$mixed-layer structure and 977 of the quasi-turbostratic structure described above $\left(R_{\mathrm{wp}}=8.67 \%\right)$.

978 Figure 12. Structure model for the $1 M$ polytype. (a) Projection on the ab plane. (b) 979 Projection along the $\mathbf{b}$ axis. Patterns as in Figure 6.

980 
Table 1. Unit-cell parameters of KBi samples as a function of temperature

\begin{tabular}{lccccc}
\hline & Polytype & $\mathrm{a}^{\mathrm{a}}$ & $\mathrm{b}^{\mathrm{a}}$ & $\mathrm{c}^{\mathrm{a}}$ & $\beta$ \\
\hline RoomT-KBi & $3 R^{-}$ & 4.928 & 2.845 & 21.492 & $90^{\circ}$ \\
$100-\mathrm{KBi}$ & $3 R^{-}$ & 4.928 & 2.845 & 21.120 & $90^{\circ}$ \\
& & & & 19.380 & \\
$150-\mathrm{KBi}$ & $3 R^{-}$ & 4.936 & 2.850 & 19.380 & $90^{\circ}$ \\
& & & & & \\
$250-\mathrm{KBi}$ & $3 R^{-}$ & 4.938 & 2.851 & 19.260 & $90^{\circ}$ \\
& $3 R^{-\mathrm{b}}$ & 4.967 & 2.868 & 19.206 & $90^{\circ}$ \\
$350-\mathrm{KBi}$ & $3 R^{-} / 3 R^{+\mathrm{c}}$ & 4.997 & 2.885 & 19.356 & \\
& $3 R^{-\mathrm{d}}$ & 4.971 & 2.870 & 21.150 & $90^{\circ}$ \\
AfterT-KBi & $1 M^{2}$ & 5.130 & 2.850 & 7.126 & $100.8^{\circ}$ \\
& & & &
\end{tabular}

${ }^{\mathrm{a}}$ Unit-cell parameters are given in $\AA$. ${ }^{\mathrm{b}}$ Unit-cell parameters of the main quasi-periodic phase. ${ }^{\mathrm{c}}$ Unit-cell parameters of the $3 \mathrm{R}^{+} / 3 \mathrm{R}^{-}$mixed layer phase. ${ }^{\mathrm{d}}$ Unit-cell parameters of the $3 \mathrm{R}^{-}$fragments in both the main phase and in the quasi-turbostratic phase 
Table 2. Indexing of the Experimental XRD Patterns of KBi Samples with $3 R$ and $1 M$ Unit Cells.

\begin{tabular}{|c|c|c|c|c|c|c|c|c|c|c|c|c|c|}
\hline \multirow{2}{*}{$\begin{array}{c}3 R \\
h k \ell^{\mathrm{a}}\end{array}$} & \multicolumn{2}{|c|}{ Room T } & \multicolumn{2}{|c|}{$100-\mathrm{KBi}$} & \multicolumn{2}{|c|}{ 150-KBi } & \multicolumn{2}{|c|}{$250-\mathrm{KBi}$} & \multicolumn{2}{|c|}{ 350-KBi } & \multicolumn{2}{|c|}{ AfterT-KBi } & \multirow{2}{*}{$\begin{array}{c}1 M \\
h k \ell^{\mathrm{a}}\end{array}$} \\
\hline & $d_{\text {exp }}^{\mathrm{b}}$ & $d_{\text {calc }^{c}}{ }^{c}$ & $d_{\exp }$ & $d_{\text {calc }}$ & $d_{\text {exp }}$ & $d_{\text {calc }}$ & $d_{\text {exp }}$ & $d_{\text {calc }}$ & $d_{\exp }$ & $d_{\text {calc }}$ & $d_{\text {exp }}$ & $d_{\text {calc }}$ & \\
\hline 003 & 7.167 & 7.164 & 7.039 & 7.040 & 6.494 & 6.468 & 6.468 & 6.420 & 6.437 & 6.442 & 7.063 & 7.000 & 001 \\
\hline 006 & 3.581 & 3.582 & 3.524 & 3.520 & 3.234 & 234 & 3.222 & 3.210 & 3.220 & 221 & .529 & 3.500 & 002 \\
\hline & & & & & & & & & & & 2.523 & $\begin{array}{l}2.526 \\
2.520\end{array}$ & $\begin{array}{c}20-1 \\
200\end{array}$ \\
\hline 201 & 2.446 & 2.445 & 2.447 & 2.445 & 2.446 & 2.445 & 2.449 & 2.447 & 2.457 & 2.465 & 2.476 & 2.481 & 110 \\
\hline 112 & 2.399 & 2.399 & 2.398 & 2.399 & 2.390 & 2.391 & 2.390 & 2.390 & 2.404 & 2.404 & 2.410 & 2.409 & $11-1$ \\
\hline 009 & & 2.388 & & 2.347 & & 2.156 & & 2.140 & & 2.147 & 2.351 & 2.333 & 003 \\
\hline 204 & - & 2.237 & 2.227 & 2.231 & & 2.197 & - & 2.195 & 2.200 & 2.210 & 2.245 & $\begin{array}{l}2.255 \\
2.241\end{array}$ & $\begin{array}{c}20-2 \\
201\end{array}$ \\
\hline 115 & 2.136 & 2.136 & 2.126 & 2.128 & 2.083 & 2.082 & 2.080 & 2.078 & 2.096 & 2.089 & $\begin{array}{l}2.131 \\
2.117 \\
1.962\end{array}$ & $\begin{array}{l}2.118 \\
1.941\end{array}$ & $\begin{array}{c}11-2 \\
112\end{array}$ \\
\hline 207 & 1.919 & 1.920 & 1.906 & 1.908 & 1.834 & 1.842 & 1.832 & 1.837 & 1.839 & 1.847 & 1.910 & 1.898 & $20-3$ \\
\hline 118 & 1.814 & 1.815 & 1.797 & 1.801 & 1.726 & 1.730 & 1.724 & 1.723 & 1.736 & 1.731 & 1.795 & 1.784 & $11-3$ \\
\hline 00.12 & 1.791 & 1.791 & 1.765 & 1.760 & 1.615 & 1.617 & 1.607 & 1.605 & 1.614 & 1.611 & & 1.750 & 004 \\
\hline 20.10 & 1.615 & 1.619 & 1.601 & 1.603 & 1.521 & 1.525 & 1.514 & 1.518 & 1.520 & 1.526 & 1.614 & 1.626 & 113 \\
\hline & & & & & & & & & & & 1.567 & 1.571 & 203 \\
\hline 11.11 & 1.530 & 1.530 & 1.515 & 1.514 & & 1.435 & 1.437 & 1.428 & 1.436 & 1.434 & 1.485 & 1.465 & $31-1$ \\
\hline & & & & & & & & & & & 1.449 & 1.447 & 310 \\
\hline $\begin{array}{l}310 \\
020\end{array}$ & 1.421 & 1.421 & 1.421 & 1.422 & 1.422 & 1.423 & 1.423 & 1.424 & 1.436 & 1.434 & 1.422 & $\begin{array}{l}1.425 \\
1.421\end{array}$ & $\begin{array}{c}020 \\
31-2\end{array}$ \\
\hline $\begin{array}{l}313 \\
023\end{array}$ & 1.395 & 1.394 & 1.394 & 1.394 & 1.390 & 1.390 & 1.392 & 1.390 & 1.403 & 1.400 & 1.395 & 1.396 & 021 \\
\hline 20.13 & 1.374 & 1.372 & 1.363 & 1.356 & 1.300 & 1.294 & 1.270 & 1.270 & 1.319 & 1.276 & 1.374 & 1.374 & 311 \\
\hline 316 & 1.322 & 1.321 & 1.321 & 1.318 & 1.300 & 1.303 & 1.308 & 1.302 & 1.287 & 1.310 & 1.328 & 1.330 & $31-3$ \\
\hline $\begin{array}{l}319 \\
029\end{array}$ & 1.224 & 1.221 & 1.222 & 1.221 & 1.223 & 1.234 & 1.221 & 1.221 & 1.187 & 1.221 & 1.239 & 1.240 & 220 \\
\hline
\end{tabular}

$\overline{{ }^{a}}$ All KBi samples are indexed as $3 R^{-}$polytypes (indices in the left-hand side column), except for sample AfterT$\mathrm{KBi}$ which is indexed as a $1 M$ polytype (indices in the right-hand side column). ${ }^{\mathrm{b}} d_{\exp }(h k \ell)$ are measured experimentally. ${ }^{\mathrm{c}} d_{\text {calc }}(h k \ell)$ values are calculated using the unit-cell parameters of the main phases listed in Table 1. 
Table 3. Atomic positions, sites occupancies and other structural parameters in hydrothermal KBi samples

\begin{tabular}{|c|c|c|c|c|c|c|c|c|c|}
\hline & & $\begin{array}{c}\text { RoomT- } \\
\mathrm{KBi}\end{array}$ & 100-KBi & 150-KBi & 250-KBi & 350 & $\mathrm{Bi}$ & Afte & $-\mathrm{KBi}$ \\
\hline & & $3 R^{-}$ & $3 R^{-}$ & $3 R^{-}$ & $3 R^{-}$ & $\begin{array}{c}\text { A layer, } \\
3 R^{-}\end{array}$ & $\begin{array}{c}\text { B layer, } \\
3 R^{+}\end{array}$ & $3 R^{-}$ & $1 M^{\mathrm{a}}$ \\
\hline $\mathrm{Mn}$ & $\mathrm{x}^{\mathrm{a}}$ & 0 & 0 & 0 & 0 & 0 & 0 & 0 & 0 \\
\hline & $y^{a}$ & 0 & 0 & 0 & 0 & 0 & 0 & 0 & 0 \\
\hline & $\mathrm{z}$ & 0 & 0 & 0 & 0 & 0 & 0 & 0 & 0 \\
\hline & OCC & 0.925 & 0.925 & 0.925 & 0.925 & 1.000 & 1.000 & 1.000 & 1.000 \\
\hline $\mathrm{O}$ & $x^{a}$ & \pm 0.333 & \pm 0.333 & \pm 0.333 & \pm 0.333 & \pm 0.333 & \pm 0.333 & \pm 0.333 & \pm 0.341 \\
\hline & $y^{a}$ & 0 & 0 & 0 & 0 & 0 & 0 & 0 & 0 \\
\hline & $\mathrm{z}$ & \pm 0.0465 & \pm 0.0473 & \pm 0.0516 & \pm 0.0519 & \pm 0.0516 & \pm 0.0516 & \pm 0.0473 & \pm 0.143 \\
\hline & $\zeta^{\mathrm{b}}$ & \pm 1.00 & \pm 1.00 & \pm 1.00 & \pm 1.00 & \pm 1.00 & \pm 1.00 & \pm 1.00 & \pm 1.00 \\
\hline & OCC & 2 & 2 & 2 & 2 & 2 & 2 & 2 & 2 \\
\hline $\mathrm{K}^{\mathrm{c}}$ & $x^{a}$ & -0.240 & -0.240 & -0.270 & -0.290 & -0.300 & -0.300 & -0.24 & -0.400 \\
\hline & $y^{a}$ & 0 & 0 & 0 & 0 & 0 & 0 & 0 & 0 \\
\hline & $\mathrm{z}$ & 0.5 & 0.5 & 0.5 & 0.5 & 0.5 & 0.5 & 0.5 & 0.5 \\
\hline & $\zeta^{\mathrm{b}}$ & 3.582 & 3.525 & 3.230 & 3.210 & 3.201 & 3.226 & 3.525 & 3.500 \\
\hline & OCC & $0.050 \times 2$ & $0.050 \times 2$ & $0.050 \times 2$ & $0.050 \times 2$ & $0.050 \times 2$ & $0.050 \times 2$ & $0.050 \times 2$ & $0.150 \times 2$ \\
\hline $\mathrm{K}^{\mathrm{c}}$ & $x^{a}$ & 0.120 & 0.120 & 0.135 & 0.145 & 0.150 & 0.150 & 0.120 & - \\
\hline & $\mathrm{y}^{\mathrm{a}}$ & \pm 0.360 & \pm 0.360 & \pm 0.405 & \pm 0.435 & \pm 0.450 & \pm 0.450 & \pm 0.360 & - \\
\hline & $\mathrm{z}$ & 0.5 & 0.5 & 0.5 & 0.5 & 0.5 & 0.5 & 0.5 & - \\
\hline & $\zeta^{\mathrm{b}}$ & 3.582 & 3.525 & 3.230 & 3.210 & 3.201 & 3.226 & 3.525 & - \\
\hline & OCC & $0.050 \times 4$ & $0.050 \times 4$ & $0.050 \times 4$ & $0.050 \times 4$ & $0.050 \times 4$ & $0.050 \times 4$ & $0.050 \times 4$ & \\
\hline $\mathrm{H}_{2} \mathrm{O}^{\mathrm{c}}$ & $x^{a}$ & 0.500 & 0.450 & - & - & - & - & 0.500 & -0.4500 \\
\hline & $y^{a}$ & 0 & 0 & - & - & - & - & 0 & 0 \\
\hline & $\mathrm{z}$ & 0.167 & 0.0167 & - & - & - & - & 0.167 & 0.5 \\
\hline & $\zeta^{\mathrm{b}}$ & 3.582 & 3.525 & - & - & - & - & 3.525 & 3.500 \\
\hline & occ & $0.070 \times 2$ & $0.070 \times 2$ & - & - & - & - & $0.060 \times 2$ & $0.190 \times 2$ \\
\hline $\mathrm{H}_{2} \mathrm{O}^{\mathrm{C}}$ & $x^{a}$ & -0.250 & -0.225 & - & - & - & - & -0.250 & - \\
\hline & $y^{a}$ & \pm 0.750 & \pm 0.675 & - & - & - & - & \pm 0.750 & - \\
\hline & $\mathrm{Z}$ & 0.167 & 0.0167 & - & - & - & - & 0.167 & - \\
\hline & $\zeta^{\mathrm{b}}$ & 3.582 & 3.525 & - & - & - & - & 3.525 & - \\
\hline & OCC & $0.070 \times 4$ & $0.070 \times 4$ & - & - & - & - & $0.060 \times 4$ & - \\
\hline $\mathrm{N}^{\mathrm{d}}$ & & $6 / 30$ & $6 / 30$ & $6 / 30$ & $6 / 30$ & $6 / 30$ & $6 / 30$ & - & $6 / 30$ \\
\hline $\mathrm{W}_{\mathrm{R}}{ }^{\mathrm{e}}$ & & $5 \%$ & $10-12 \%$ & $12 \%$ & $17 \%$ & $10 \%$ & $30 \%$ & - & $30 \%$ \\
\hline $\mathrm{CSD}^{\mathrm{f}}$ & & 350 , & 230 & 230 & 180 & 230 & 200 & - & 250 \\
\hline
\end{tabular}

${ }^{\mathrm{a}} \mathrm{x}$ and $\mathrm{y}$ atomic positions are expressed in fraction of unit-cell $a$ and $b$ parameters. $\mathrm{x}$ positions are given in projection normal to the ab plane. ${ }^{\mathrm{b}}$ Position $\zeta$ along $c$ is expressed in $\AA$ to emphasize the thickness of layer and interlayer polyhedra. ${ }^{c}$ For $\mathrm{K}$ and $\mathrm{H}_{2} \mathrm{O}$ only 3 of the 6 equivalent sites are reported. Additional sites are obtained by the symmetry operation $x=-x$ and $z=-z$. ${ }^{\mathrm{d}}$ The extension of the coherent scattering domains perpendicular to the layer plane is expressed in number of layers $\mathrm{N}$ (mean/average). ${ }^{\mathrm{e}} \mathrm{W}_{\mathrm{R}}$ is the occurrence probability of random stacking faults for the well-crystallized phases. ${ }^{\mathrm{f}} \mathrm{CSD}$ is the radius of the coherent scattering domains in the ab plane. For the quasi-turbostratic phase present in all samples, $\mathrm{W}_{\mathrm{R}}=75 \%$ and CSDS $=70 \AA$. The values of Debye-Waller thermal factor (B) are $0.5,1.0,2.0$ and 2.0 for $\mathrm{Mn}_{\text {layer }}, \mathrm{O}_{\text {layer }}, \mathrm{K}_{\text {interlayer }}$ and $\mathrm{H}_{2} \mathrm{O}_{\text {interlayer, respectively. }}$ 
Table 4. Selected inter-atomic distances (in $\AA$ ) in hydrothermal KBi samples

\begin{tabular}{|c|c|c|c|c|c|c|c|c|c|}
\hline & & \multirow{2}{*}{$\begin{array}{c}\text { RoomT- } \\
\text { KBi }\end{array}$} & \multirow{2}{*}{$\begin{array}{c}100-\mathrm{KBi} \\
3 R^{-}\end{array}$} & \multirow{2}{*}{$\frac{150-\mathrm{KBi}}{3 R^{-}}$} & \multirow{2}{*}{$\begin{array}{c}250 \mathrm{KBi} \\
3 R^{-}\end{array}$} & \multicolumn{2}{|c|}{ 350-KBi } & \multicolumn{2}{|c|}{ AfterT-KBi } \\
\hline & & & & & & $3 R^{-}$ & $3 \boldsymbol{R}^{+}$ & $3 \boldsymbol{R}^{-}$ & $1 M$ \\
\hline Height of Mn layer & & 2.000 & 2.000 & 2.000 & 2.000 & 2.000 & 2.000 & 2.000 & 2.000 \\
\hline $\mathrm{Mn}_{\text {layer }}-\mathrm{Mn}_{\text {layer }}$ & $\times 3$ & 2.845 & 2.845 & 2.850 & 2.851 & 2.868 & 2.885 & 2.870 & $\begin{array}{l}2.934 \times 1 \\
2.850 \times 2\end{array}$ \\
\hline $\mathrm{Mn}_{\text {layer }}-\mathrm{O}_{\text {layer }}$ & $\times 6$ & 1.923 & 1.923 & 1.924 & 1.927 & 1.935 & 1.943 & 1.935 & $\begin{array}{l}1.923 \times 4 \\
2.015 \times 2 \\
\end{array}$ \\
\hline Height of interlayer & & 5.164 & 5.040 & 4.460 & 4.420 & 4.402 & 4.452 & 5.050 & 5.000 \\
\hline K-O short & $\times 4$ & 2.970 & 2.917 & 2.696 & 2.709 & 2.708 & 2.734 & 2.928 & $2.703 \times 1$ \\
\hline $\mathrm{K}_{\text {interlayer }}-\mathrm{O}_{\text {layer }}$ long & $\times 2$ & 3.330 & 3.282 & 2.968 & 2.855 & 2.855 & 2.881 & 3.298 & $2.831 \times 1$ \\
\hline Average $\mathrm{K}_{\text {interlayer }}-\mathrm{O}_{\text {layer }}$ & $\times 6$ & 3.090 & 3.039 & 2.787 & 2.758 & 2.757 & 2.783 & 3.051 & $2.767 \times 2$ \\
\hline $\mathrm{K}_{\text {interlayer }}-\mathrm{H}_{2} \mathrm{O}_{\text {interlayer }}$ & $\begin{array}{l}\times 1 \\
\times 2\end{array}$ & $\begin{array}{l}2.924 \\
3.222\end{array}$ & $\begin{array}{l}2.922 \\
3.222\end{array}$ & - & - & - & - & $\begin{array}{l}2.949 \\
3.251\end{array}$ & $\begin{array}{l}2.713 \times 2 \\
2.862 \times 2 \\
3.161 \times 2 \\
\end{array}$ \\
\hline $\mathrm{O}_{\text {layer }}-\mathrm{H}_{2} \mathrm{O}_{\text {interlayer }}$ & $\times 2$ & 2.705 & 2.650 & - & - & - & - & 2.658 & $\begin{array}{l}2.616 \times 1 \\
2.720 \times 1\end{array}$ \\
\hline $\mathrm{O}-\mathrm{H}_{2} \mathrm{O}-\mathrm{O}$ angle & & $144.71^{\circ}$ & $143.90^{\circ}$ & - & - & - & - & $143.67^{\circ}$ & 139.56 \\
\hline
\end{tabular}



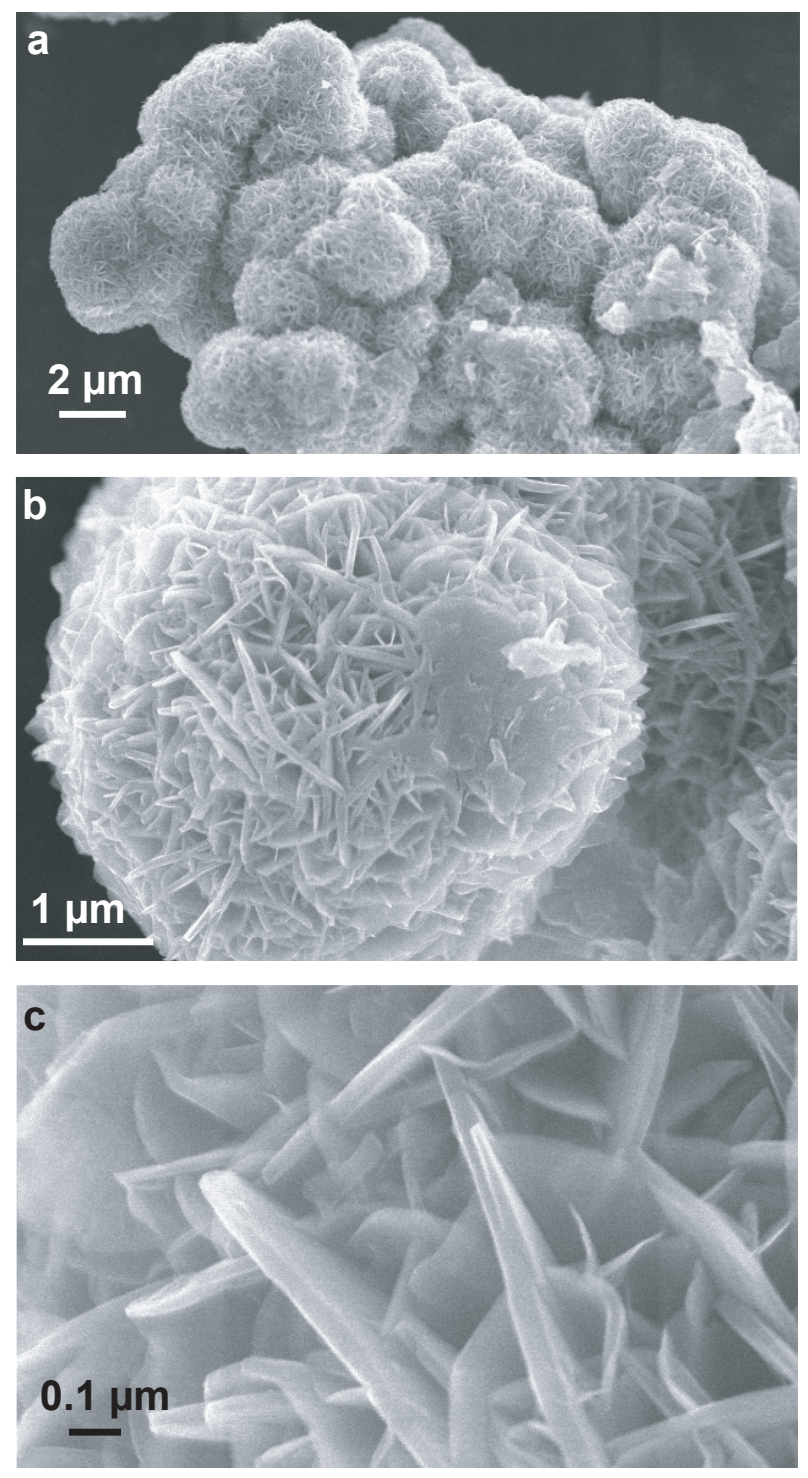

Gaillot et al. - Fig 01 


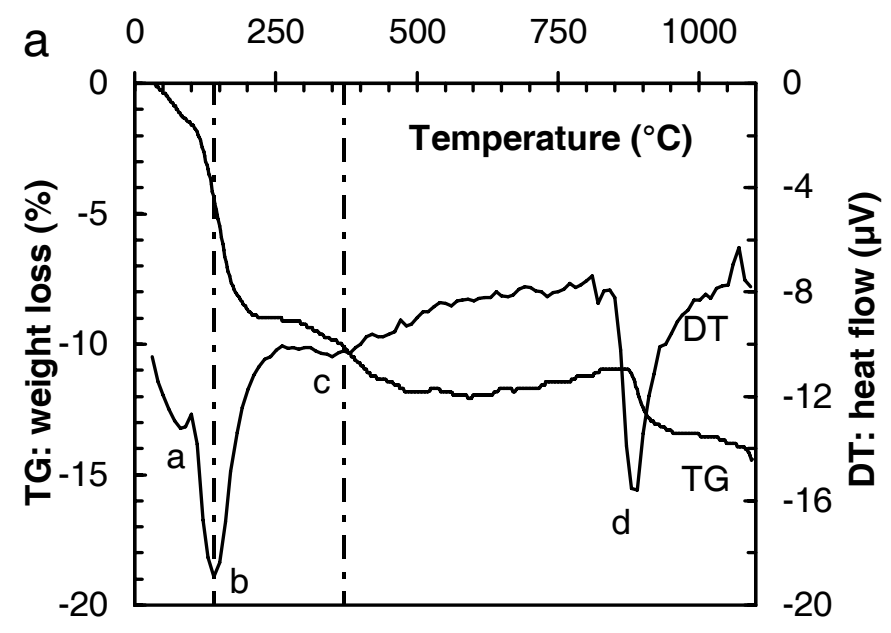

Gaillot et al. - Fig 02a 


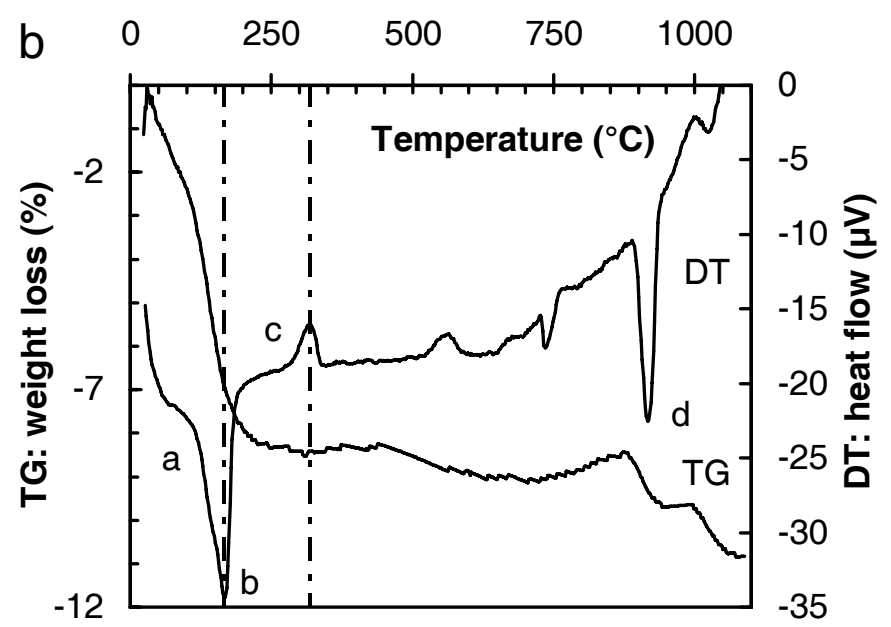

Gaillot et al. - Fig 02b 


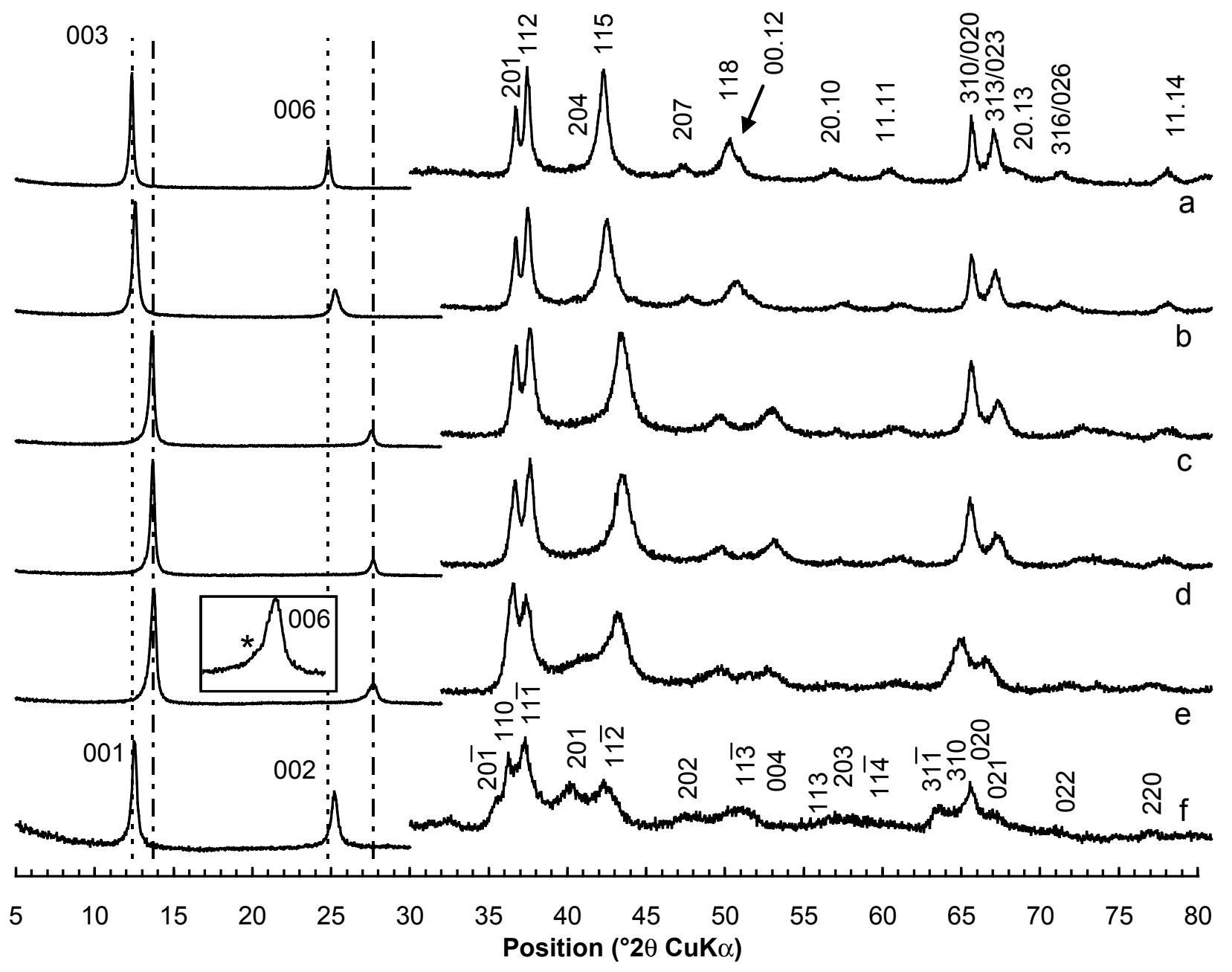

Gaillot et al. - Fig 03 


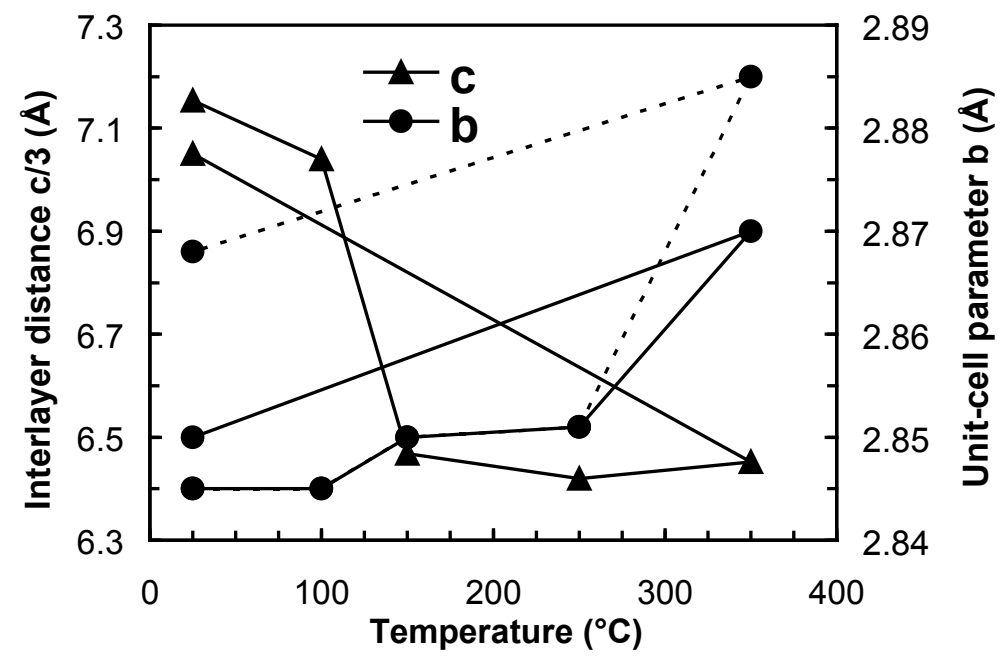

Gaillot et al. - Fig 04 


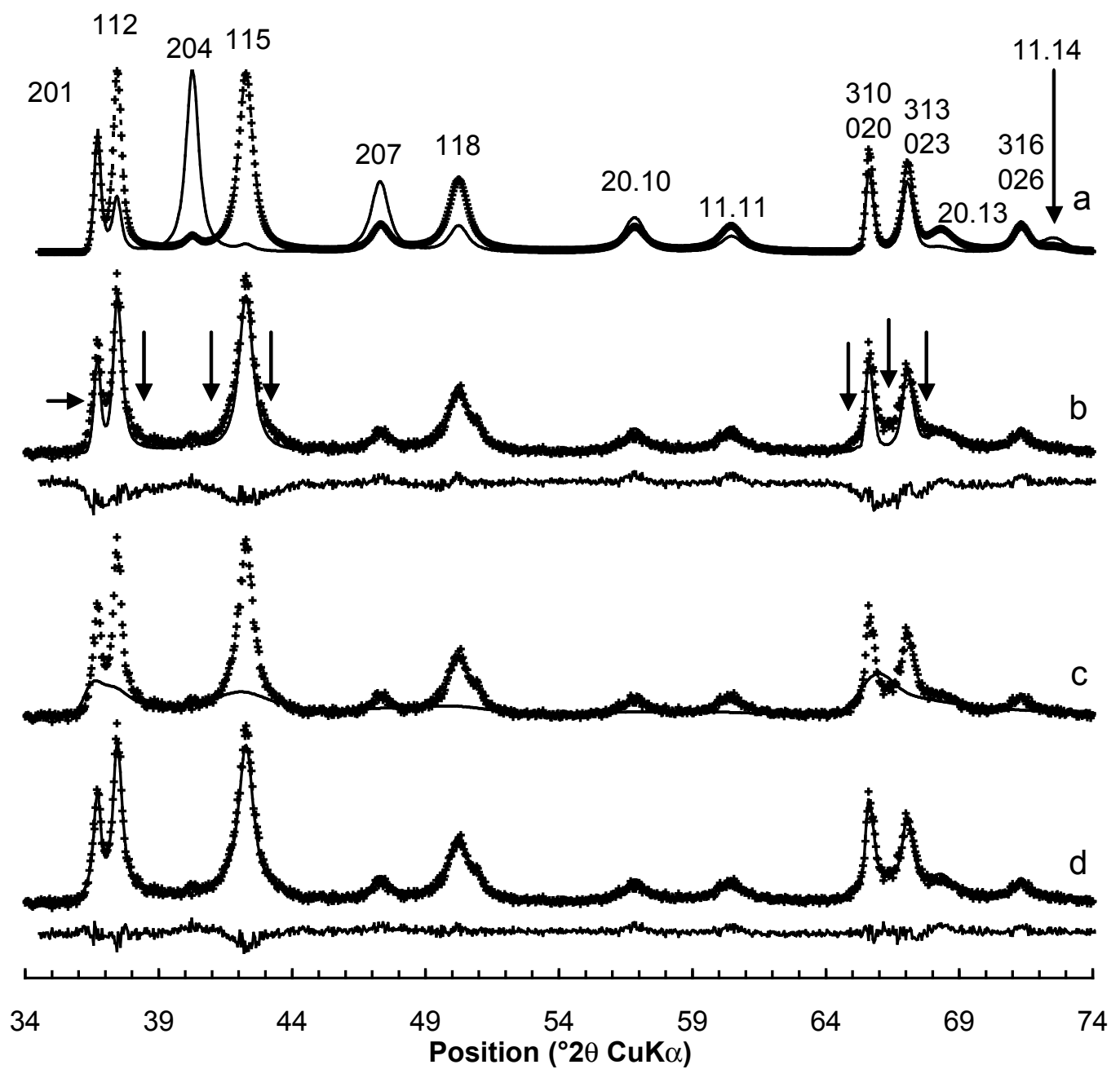

Gaillot et al. - Fig 05 

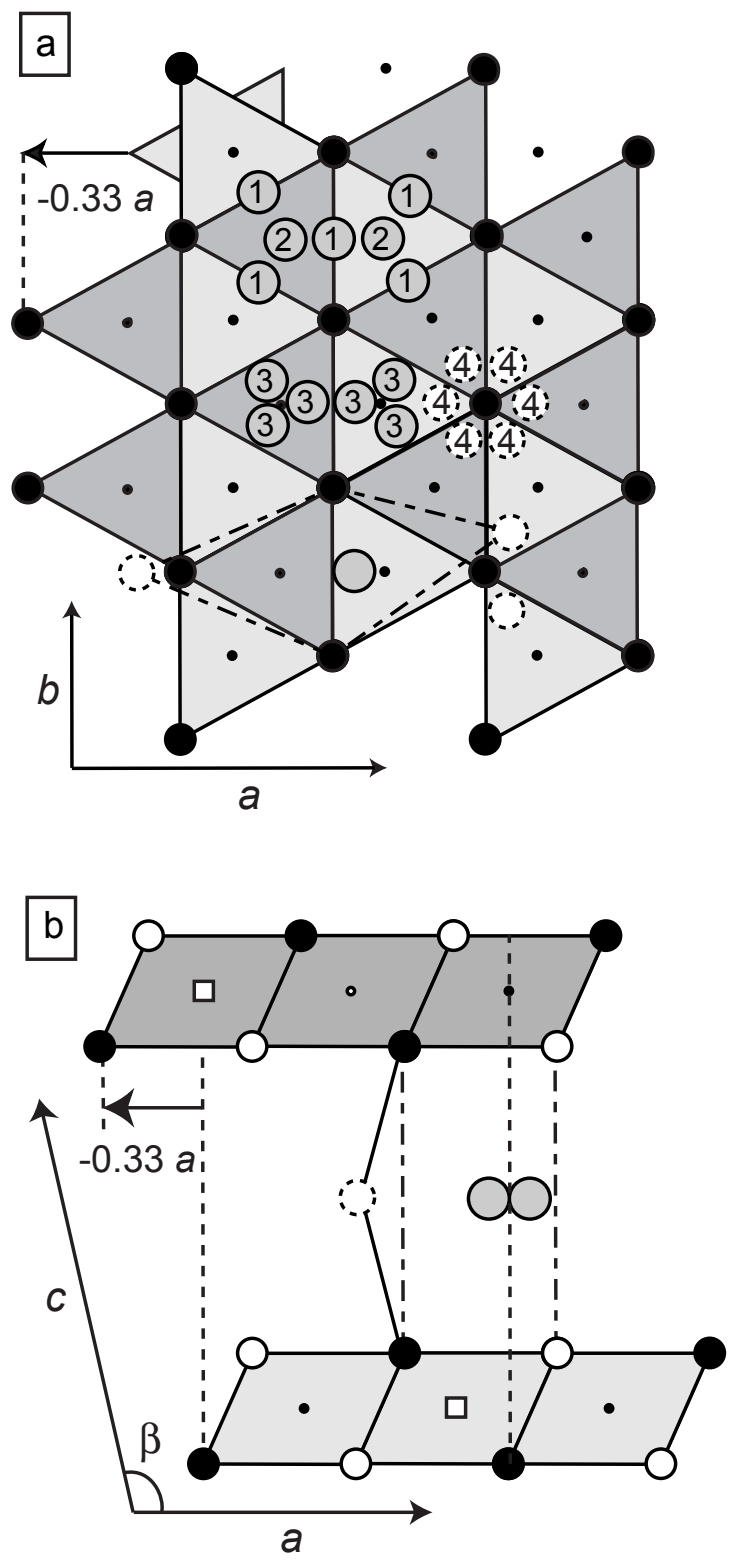

Gaillot et al. - Fig. 06 

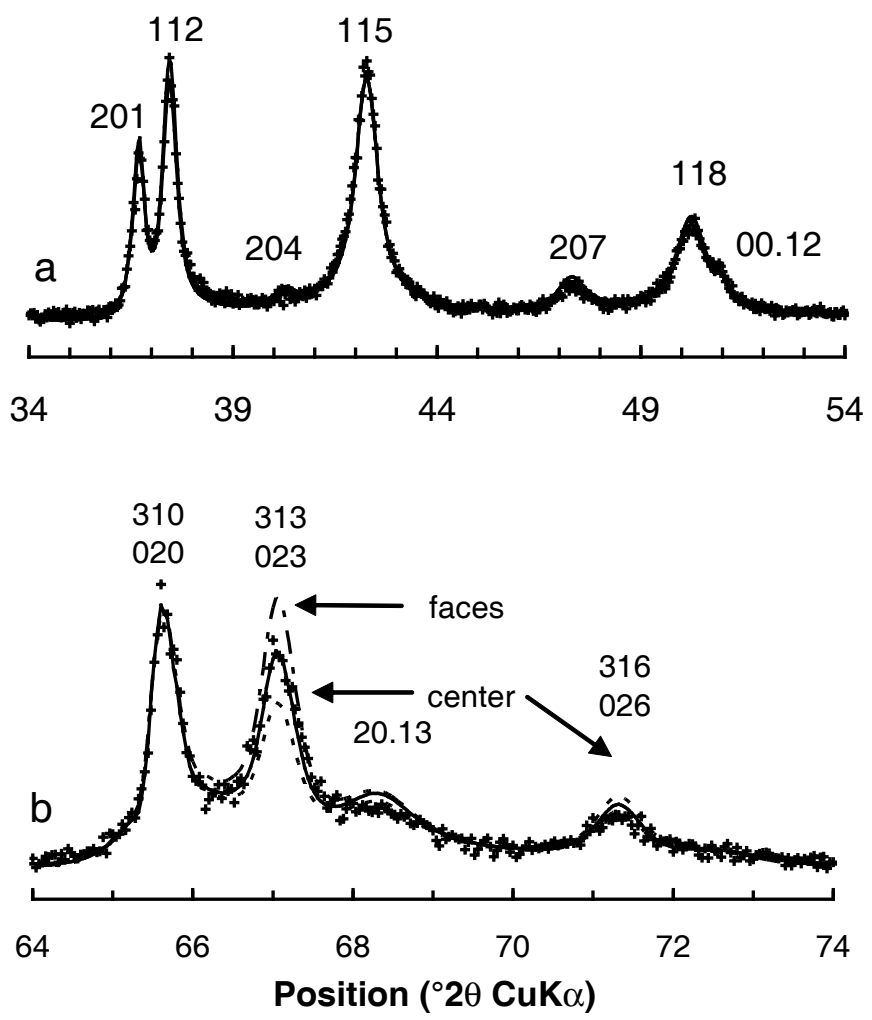

Gaillot et al. - Fig 07 

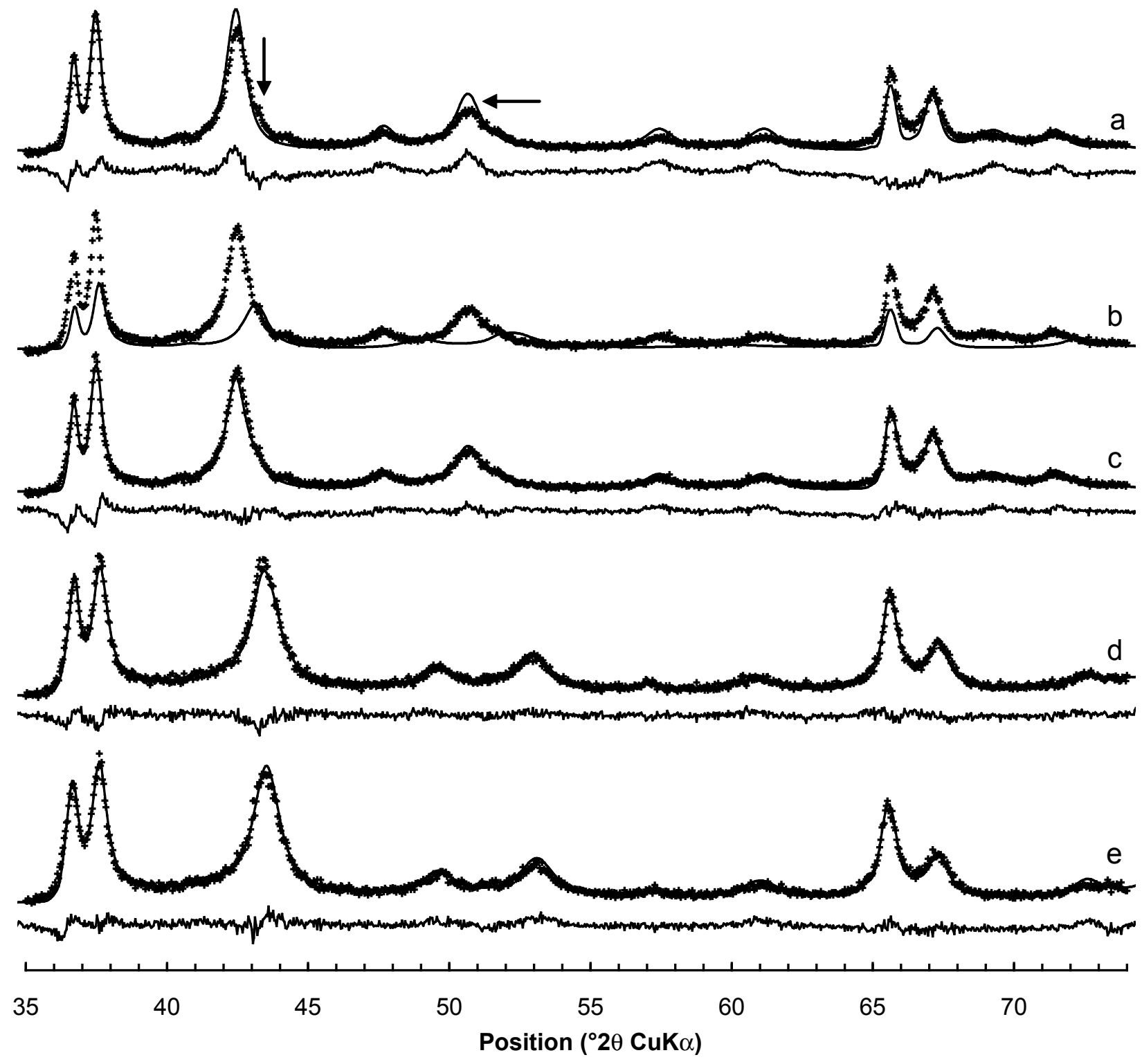

Gaillot et al. - Fig 08 


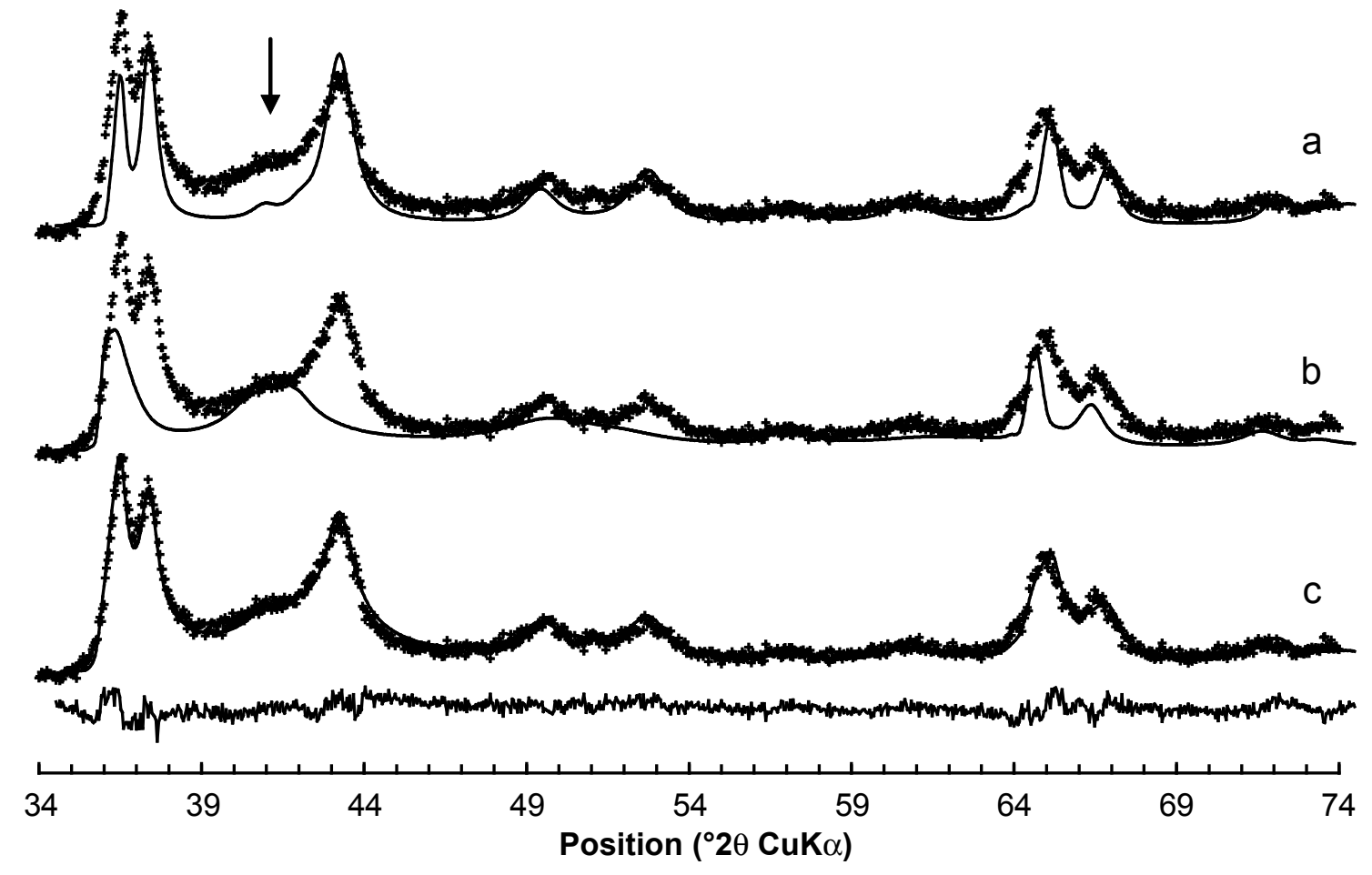

Gaillot et al. - Fig 09 

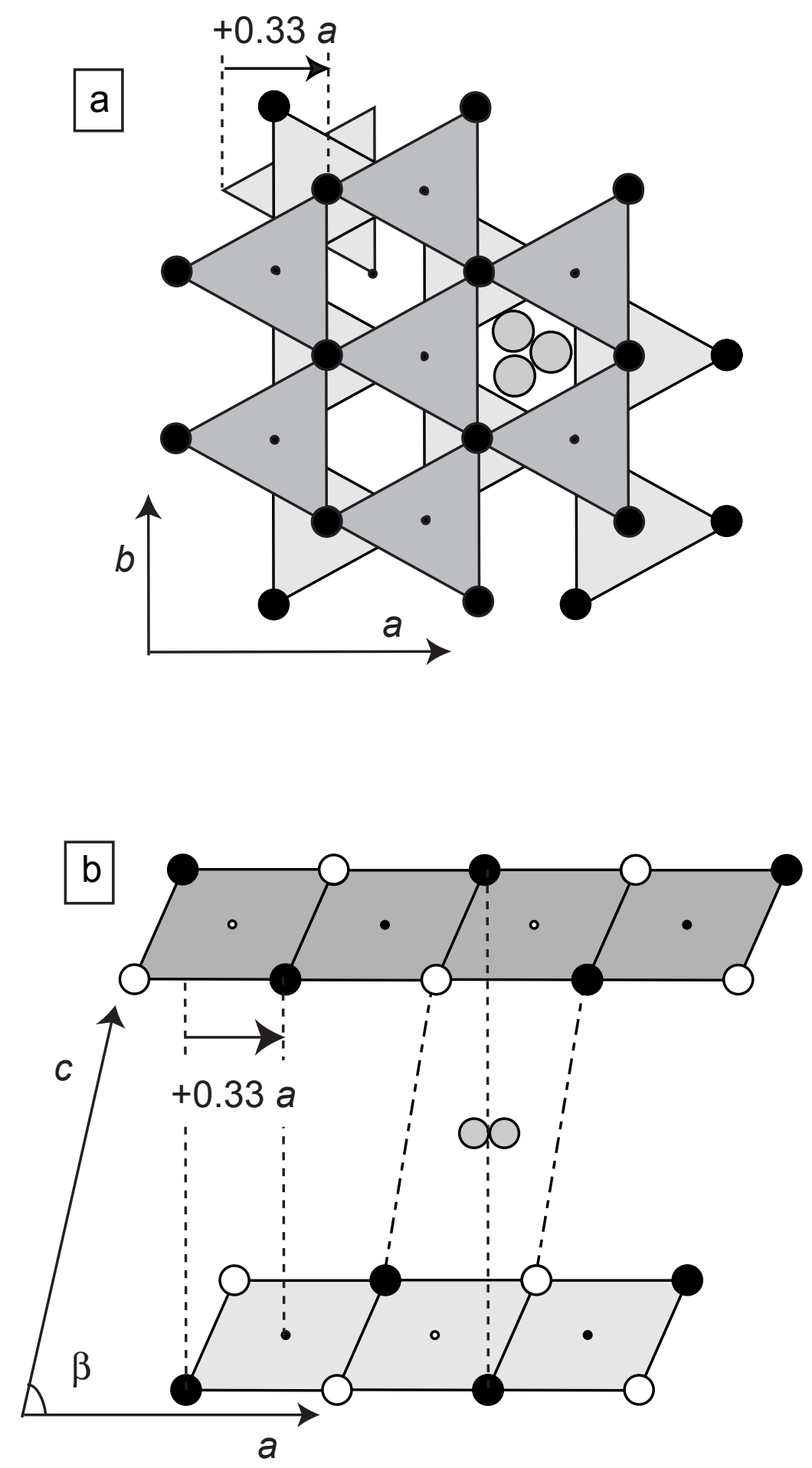

Gaillot et al. - Fig 10 


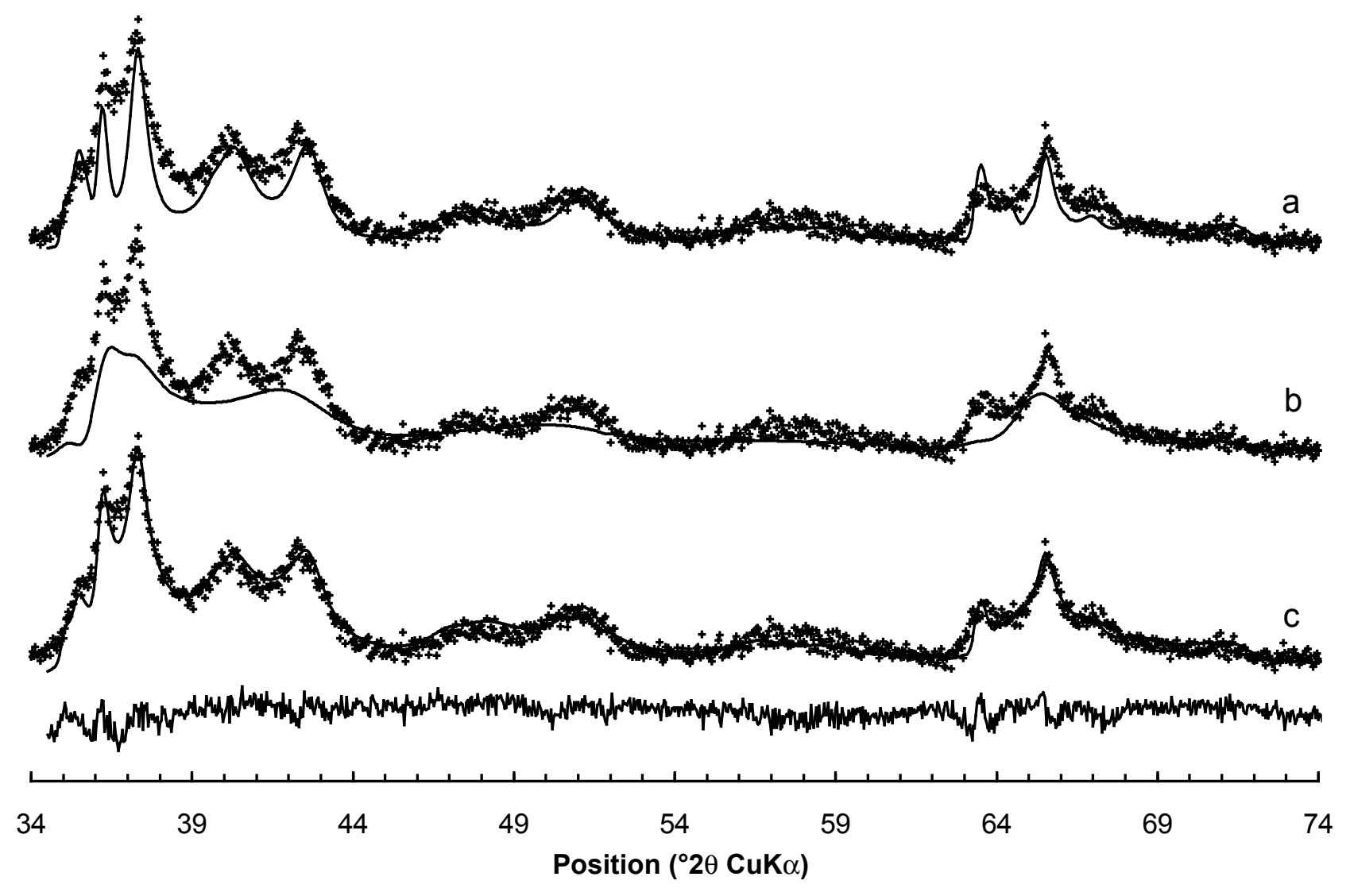

Gaillot et al. - Fig 11 

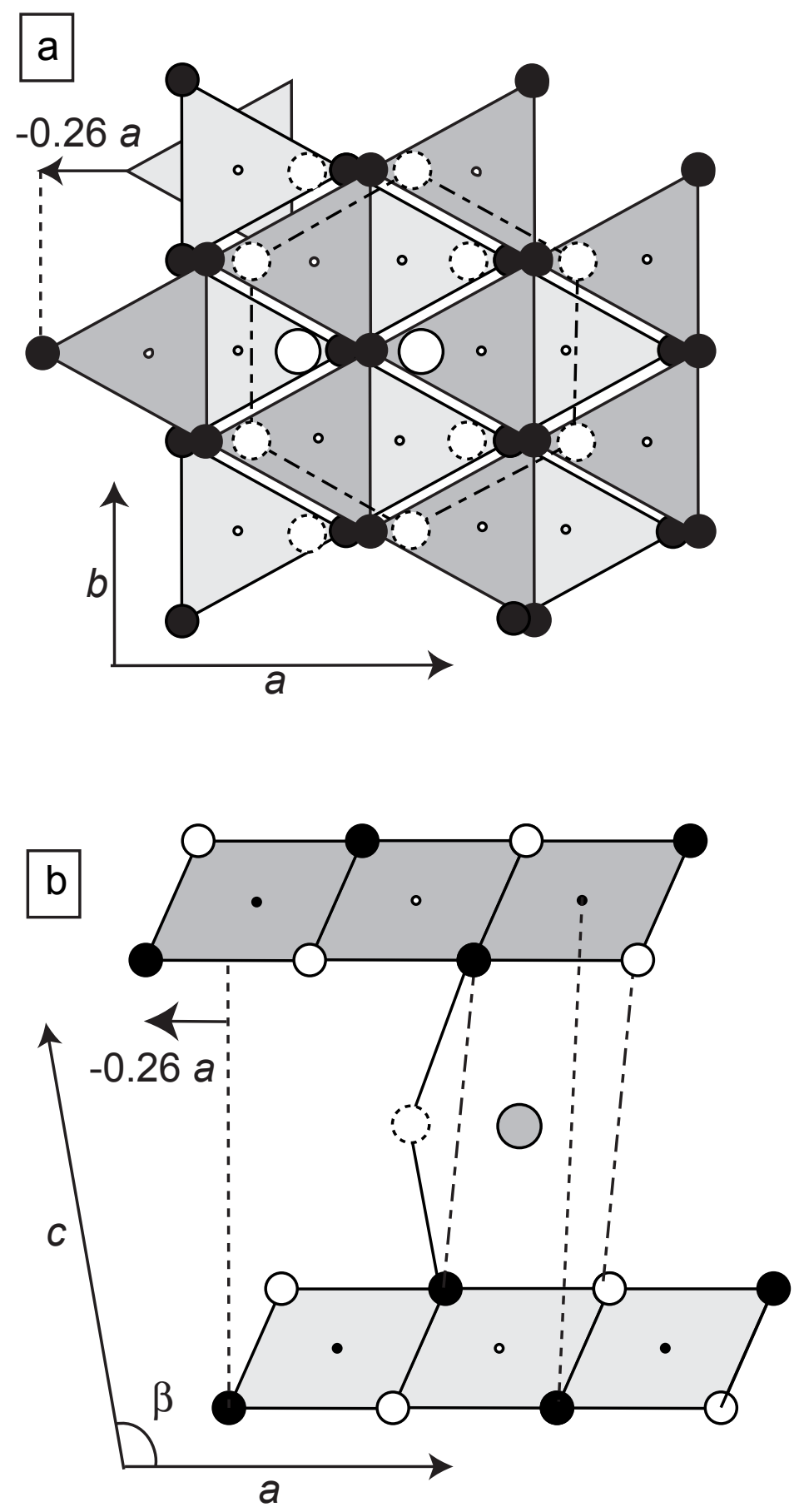

Gaillot et al. - Fig 12 